\title{
Los periplos atlánticos norteafricanos de Polibio y Juba II trasmitidos por Plinio (N.H., V, 9-10)
}

\author{
Alfredo Mederos Martín \\ Universidad Autónoma de Madrid \\ alfredo.mederos@uam.es
}

Recibido: 7 de marzo de 2013

Aceptado: 6 de julio de 2013

\section{RESUMEN}

El Periplo de Polibio, realizado al final la Tercera Guerra Púnica, durante el verano de 146 a.C., debió de tener como objetivo informar a las antiguas ciudades aliadas fenicias, que Cartago había sido destruida y la fachada mediterránea y atlántica norteafricana pasaba a estar dentro de la órbita política de Roma. Al Periplo se le han atribuido dos fuentes, pues ambas terminan en el entorno del río Darat. La más antigua es del propio Polibio (Plin., N.H., V, 10), que también aprovecha textos anteriores con una toponimia más antigua, que se retrotrae hasta el periplo de Hannón, caso de Kérne, Banbotum o del Theôn Óchema. La segunda fuente (Plin., N.H., V, 9) no puede ser Polibio. Aunque se ha atribuido a Agripa, debió ser la expedición de Juba II, quien utiliza datos toponímicos más recientes y menciona a los getulos, desconocidos hasta los libros de Salustio. Juba II envió una expedición naval a inicios de su reinado, desde el 25 a.C., al sur de la Mauretania, cuya parte final, ya insular, relativa a la exploración de las Islas Canarias, estaba bien identificada (Plin., N.H., VI, 202-205). Se trató de un viaje de unos 21 días de navegación y 1.176.000 pasos entre Gadir o Septem Fratres, alcanzando hasta el río Darat [Drâa] o el río Banbotum [Aoueri en Santa Cruz de Mar Pequeña].

Palabras clave: Periplo. Norte de África. Polibio. Juba II. Getulos.

\section{The North African Atlantic Periplus of Polybius and Juba II transmitted by Pliny (N.H., V, 9-10)}

\begin{abstract}
The Periplus of Polybius, conducted at the end of the Third Punic War, during the summer of 146 BC, must be aimed to inform to the ancient Phoenician allied cities that Carthage has been destroyed and the Mediterranean and North African Atlantic façade just fall within the Rome's political orbit. The Periplus has been attributed to two sources, as both end up around the river Darat. The oldest one of Polybius' himself (Plin., N.H., V, 10), which also uses previous texts with most ancient toponymy, which goes back to the Periplus of Hanno, as Kérne, Banbotum or Theôn Óchema. The second source (Plin., N.H., V, 9) can not be Polybius. Althought it has been attributed to Agripa, must be the expedition of Juba II, who uses more recent place names and mentions the Gaetulians, unknown until the books of Sallust. Juba II sent a naval expedition, early in his reign, from $25 \mathrm{BC}$, south of Mauretania, whose insular final part, the exploration of the Canary Islands, was well identified (Plin., N.H., VI, 202-205). It was a voyage of about 21 days sailing, 1.176.000 passuum, between Gadir or Septem Fratres, reaching the river Darat [Drâa] or river Banbotum [Aoueri, Santa Cruz de Mar Pequeña].
\end{abstract}


Key words: Periplus. North Africa. Polybius. Juba II. Gaetulians.

Sumario: 1. Introducción. 2. Fuentes. 3. Cronología. 4. Objetivos del periplo. 5. Punto de partida, miembros de la expedición y flota. 6. Trayecto. 7. Estudio crítico. 8. Límite del viaje y trayecto de regreso. 9. Conclusiones. 10. Anexo.

\section{Introducción ${ }^{1}$}

El Periplo de Polibio, realizado al final la Tercera Guerra Púnica, en 146 a.C., es reflejo de la nueva hegemonía romana, ya no sólo en el Mare Nostrum o Mar Mediterráneo, sino en su proyección hacia el Mar Exterior u Océano Atlántico, ante la necesidad de conocer las rutas previamente transitadas por gaditanos y cartagineses.

La visión geográfica y científica de Polibio responde a una concepción romanocéntrica, que enfatiza la importancia que supone la pax romana para disponer de conocimientos verídicos de las regiones anteriormente inaccesibles, por su infravaloración de los pueblos bárbaros a los que considera ignorantes científicamente, ${ }^{2}$ señalando su "propósito de rectificar la ignorancia de nuestros predecesores en estas cuestiones". ${ }^{3}$

Polibio lo expresa perfectamente en una parte de su obra, "en nuestros días, debido al imperio de Alejandro en Asia y al dominio de los romanos de las restantes partes del mundo, casi todo el orbe ha llegado a ser navegable o transitable (...) Por ello deberíamos conocer mejor y con mayor exactitud lo que antes se ignoraba (...) Será nuestro deseo, en consecuencia, instruir de la forma más plena a los que se preocupan y tienen interés por estos conocimientos. En atención a ello, sobre todo, hemos soportado los peligros y fatigas que nos acaecieron en un viaje por Libia, Iberia y, también, por la Galia y el mar que circunda estos países por el lado exterior. Y todo con el propósito de rectificar la ignorancia de nuestros predecesores en estas cuestiones". ${ }^{4}$ Este texto nos informa de que Polibio realizó dos periplos atlánticos, uno hacia el Norte, costeando Hispania y la Galia, y otro hacia el Sur, bordeando la costa africana, ambas antiguas rutas fenicias, frecuentadas después por cartagineses y gaditanos.

Desde el primer tratado de Roma con Cartago, a finales del siglo VI a.C., en 509 a.C., ${ }^{5}$ la naciente potencia africana se había reservado como territorio exclusivo la

1 Este trabajo se adscribe a los proyectos "La ciudad fenicio-púnica de Útica", HAR2011-29880, del Ministerio de Educación y Ciencia, bajo la dirección de J. L. López Castro y "Descubrimiento y poblamiento de las Islas Canarias (1100 AC-500 DC)", de la Dirección General de Patrimonio Histórico del Gobierno de Canarias, codirigido por G. Escribano y A. Mederos. Queremos agradecer a E. Lipinski atender amablemente a nuestras consultas y en particular a Alicia $\mathrm{M}^{\mathrm{a}}$ Canto su atenta revisión del texto y sus traducciones de Plinio (V, 9-10), del título de la obra perdida de Polibio (XXXIV, frag. A7) y de Veleyo Patérculo (I, 13, 3).

2 TeXIER 1976, 401, tablas 1 y 3.

3 Pol. III, 59, 8. Para la obra de Polibio se han utilizado las ediciones de la Biblioteca Clásica Gredos $\left(\mathrm{n}^{\circ}\right.$ 38, libros I-IV, de 1981 y n $^{\circ} 58$, libros XVI-XXXIX, de 1983, ambos con traducción de M. Balasch Recort), CSIC (para el libro III, de 1989, con traducción de A. Díaz Tejera) y The Loeb Classical Library (nº 137, vol. II, 3-4, de 2010, y n 161 , vol. VI, 28-29 y Fragmentos, de 2012, ambos a cargo de W. R. Paton [trans.], F. W. Walbank y C. Habicht [revised]).

4 Pol. III, 59, 3, 6-7, traducción de A. Díaz Tejera.

5 Pol. III, 22, 1. 
región empórica de las Sirtes, ${ }^{6}$ pero a partir del segundo tratado, en 348 a.C., Cartago especificó expresamente "En Cerdeña y Libia ningún romano comerciará ni fundará ciudades y que no arribe allí sino para proveerse de víveres o reparar su embarcación. Y si una tempestad le obliga a tomar puerto, en cinco días deberá partir", ${ }^{7}$ indicativo de su etapa de mayor hegemonía mediterránea entre la segunda mitad del siglo IV a.C. y la primera mitad del siglo III a.C., 348-205 a.C.

\section{Fuentes}

Sin embargo, al no conservarse el texto del libro 34 de la Historia de Polibio, ni su obra Sobre la habitabilidad bajo la línea equinoccial, ${ }^{8}$ no disponemos de sus datos directamente, y de las referencias presentes en Plinio $^{9}$ no sabemos si toda la información procede de su viaje, o si éste utilizó otras fuentes complementarias.

Por otra parte, un notable grupo de autores sigue enfatizando el carácter literario de estos periplos, negando su realidad histórica, en particular el de Hannón, cuya toponimia es aprovechada por Polibio. Este periplo de Hannón se ha interpretado recientemente como un texto el siglo III a.C. redactado en griego en Alejandría, ${ }^{10}$ de finales del siglo II a.C., elaborado también en Alejandría, ${ }^{11} \mathrm{o}$ un texto griego adaptado por Jenofonte de Lámpsaco a mediados siglo II a.C. ${ }^{12}$

La discusión más habitual sobre las fuentes del Periplo de Polibio es si la primera parte del texto corresponde a Agripa, por la mención de su nombre junto a Lixus, Agrippa Lixum. Una de las opciones es la de Harduinus ${ }^{13}$ que lo consideraba una glosa posterior al texto original de Plinio, por lo que todo el texto sería obra de Polibio; así se defiende desde Klotz, ${ }^{14}$ considerando estos autores que sólo el dato de la distancia entre Gadir y Lixus procede de Agripa.

Sin embargo, Agrippa Lixum aparece en tres manuscritos, el Parisinus Latinus 6795, el Vaticanus Latinus 3861 y el Florentinus Riccardianus y, desde su sugerencia por Riese, ${ }^{15}$ se ha atribuido la primera parte a unos Comentarios de Agripa, publicados por Augusto, que completaban el Orbis pictus.

6 Pol. III, 23, 2.

7 Pol. III, 24, 11.

8 Pol. XXXIV, frag. A7, a partir de Gemin. Elem. Astron., XVI, 32. Traducción de A. M Canto.

9 Plin. N.H., V, 9. Para la Historia Natural de Plinio se han empleado la traducción inédita de Alicia M. Canto de Plinio (V, 9-10) y las ediciones de la Biblioteca Clásica Gredos (nº 250, libros III-VI, de 1998, con traducción de A. Fontán, I. García Arribas y E. del Barrio Sanz), Fontes Hispaniae Antiquae (vol. VII, 113180, de 1987, editado por V. Bejarano), Teubner (libros I-VI, de 1906, editado por C. Mayhoff), Les Belles Lettres (libros V, 1-46, de 1980, editado por J. Desanges) y The Loeb Classical Library (n ${ }^{\circ} 371$, vol. V, libros XVII-XIX, de 1971, editado por H. Rackham).

10 Gómez Espelosín 1994, 135; ID. 2000, 150, 154.

11 García Moreno 1993, 68.

12 GonzÁlez Ponce 2003-07, 102 n. 29; ID. 2009; ID. 2010.

13 Harduinus 1685.

14 Klotz 1906, 14-15; Detlefsen 1906, 43; Berthelot 1927, 264; Thouvenot 1939, 116; Pédech 1955 , 321.

15 Riese 1878, 5 n. frag. 25; Müller 1883-1901, 575; Strenger 1913, 28-29; Gsell 1918, 391; Mauny 1949, 54-56, 55 fig. 1; Desanges 1978, 124-125, n. 27; Peretti 1979, 378 n. 411, 393; Gozalbes $2002,84$. 
Se ha señalado que Polibio no usaba la denominación de Gaditanum fretum o Estrecho Gaditano, sino la de Columnas de Hércules, ${ }^{16}$ y eso apoyó aún más su atribución a Agripa. El punto de referencia podría ser también Ceuta, el fretum Septemgaditanum del Geógrafo de Rávena (III, 12). ${ }^{17}$

Así, actualmente, la hipótesis más aceptada, a partir de la propuesta de Mauny ${ }^{18}$ es considerar que el texto de Plinio está reduplicado por el uso de dos fuentes diferentes, el párrafo V, 9 procedente de Agripa, y el párrafo V, 10, original de Polibio, pues ambas terminan entorno al río Drâa.

Por otra parte, para Pédech ${ }^{19}$ los datos del interior de la Mauretania proceden de Juba II, trasmitidos probablemente por Agripa, que dispondría de ellos por tener situada su segunda residencia real en Volubilis y haber instalado las factorías de púrpura en Mogador. En este sentido, argumenta que las distancias del río Anatis al Atlas -de 496 millas- o de Lixus al Atlas -de 205 millas- serían aportadas por Juba II a partir de un itinerario terrestre.

Que al menos los datos de algunos pueblos del interior como los gétulos autololes deriven de Agripa, quien a su vez pudo tomarlos de Juba II, lo acepta Desanges. ${ }^{20}$ Polibio nunca distingue a los gétulos en los textos que escribe sobre Cartago y África, ${ }^{21}$ que se enfrentan por primera vez contra Roma junto con Yugurta el 108 a.C. en el sur de Constantina ${ }^{22}$ y son citados en el primer párrafo del Periplo.

Un matiz apuntado por Pédech ${ }^{23}$ es que los datos atribuidos a Agripa pueden derivar de Juba II, que recogió los datos en millas romanas, sugiriendo Gozalbes ${ }^{24}$ que lo lógico es que hubieran sido obtenidos en una expedición enviada por Juba II, lo que parece la explicación más razonable, ya que no tenemos constancia de ningún periplo o expedición enviada por Agripa. Esto lo apoya Pédech ${ }^{25}$ también en la similitud de las cifras de 625 millas entre las Purpurarias, que sitúa en Mogador, y las Islas Canarias, por ser casi iguales que las 616 millas hasta el promontorio Hespéru Keras que sitúa en Cabo Juby. También el propio Mauny ${ }^{26}$ barajó esta posibilidad de Juba II como fuente, al considerar que “Juba y Agripa son los 'candidatos' más serios”, pero se inclinó por Agripa.

Una tercera hipótesis fue desarrollada por Tauxier, quien nunca la publicó en un texto extenso, aunque comentó que lo tenía elaborado. Este autor considera que el texto de Plinio cuenta con dos fuentes diferentes. La primera de Polibio, que Plinio no consulta directamente sino trasmitido de segunda o tercera mano por un griego contemporáneo del emperador Claudio. La segunda parte del texto usaría como fuen-

16 PÉDECH 1955, 327.

17 Desanges 1978, 129.

18 Mauny 1949, 53; Desanges 1978, 125; Santana et alii 2002, 133; Gozalbes 2002, 84.

19 PÉDECH 1955, 325-327.

20 Desanges $1980,113$.

21 Desanges 1978, 125

22 Sal. Iug., LXXX, 1. Para esta obra se han consultado las ediciones de la Biblioteca Clásica Gredos $\left(\mathrm{n}^{\circ}\right.$

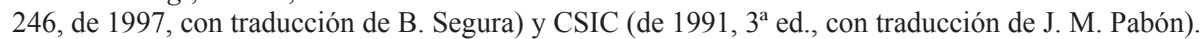

23 PÉDECH 1955, 327.

24 Gozalbes 2011, 163.

25 PÉDECH 1955, 329 n. 1.

26 Mauny 1949, 53. 
te un rutero cartaginés más antiguo, ${ }^{27}$ que incluso sugiere retrotraer a época fenicia, ${ }^{28}$ el cual llegaría hasta el río Sala, ${ }^{29}$ probablemente porque a partir de este punto no se indican distancias, aunque considera que Polibio tuvo conocimientos de la fachada meridional, al mencionar a los ríos Darat o Drâa y el Banbotum o Seguia el-Hamra.

Como puede apreciarse, aunque hay autores que atribuyen todo el texto a Polibio (Gossellin, Thouvenot, Pédech), en general se acepta que hay dos fuentes: el primer texto sería de Polibio (Tauxier), Agripa (Gsell, Mauny, Desanges, Santana et alii) o Juba II (Gozalbes) y la segunda parte sería de Polibio (Gsell, Mauny, Desanges, Santana et alii) o de un rotero cartaginés (Tauxier).

\section{Cronología}

La fecha del viaje se ha situado al inicio de la Tercera Guerra Púnica, ${ }^{30}$ el 149 a.C., aunque resulta difícil que así fuera, pues Escipión no fue nombrado por el Senado hasta la primavera del 147 a.C. También se ha propuesto ese año del 147 a.C., ${ }^{31} 146$ a.C., ${ }^{32} 145$ a.C., ${ }^{33} 145-144$ a.C.,${ }^{34}$ o 140 a.C. ${ }^{35}$

La hipótesis más aceptada es que se realizó en un intervalo máximo de cinco meses, aprovechando la mejor época para la navegación, entre la caída de Cartago en abril de 146 a.C. ${ }^{36}$ y la presencia de Polibio en Corinto en septiembre del mismo año, ${ }^{37}$ lo que implica un trayecto no demasiado largo, cuya ida y vuelta se ha situado en unos tres meses ${ }^{38}$ aunque precisamente por lo acotado de las fechas Gsell ${ }^{39}$ prefiere el año anterior de 147 a.C.

Sin embargo, cabe plantearse entonces cuándo se realizó el trayecto opuesto por la costa atlántica europea, pues lo más lógico es que se hubiesen efectuado en años sucesivos, desde nuestro punto de vista primero el africano en 146 a.C., y al año siguiente -el 145 a.C.- el de la fachada atlántica, para completar los resultados del primero.

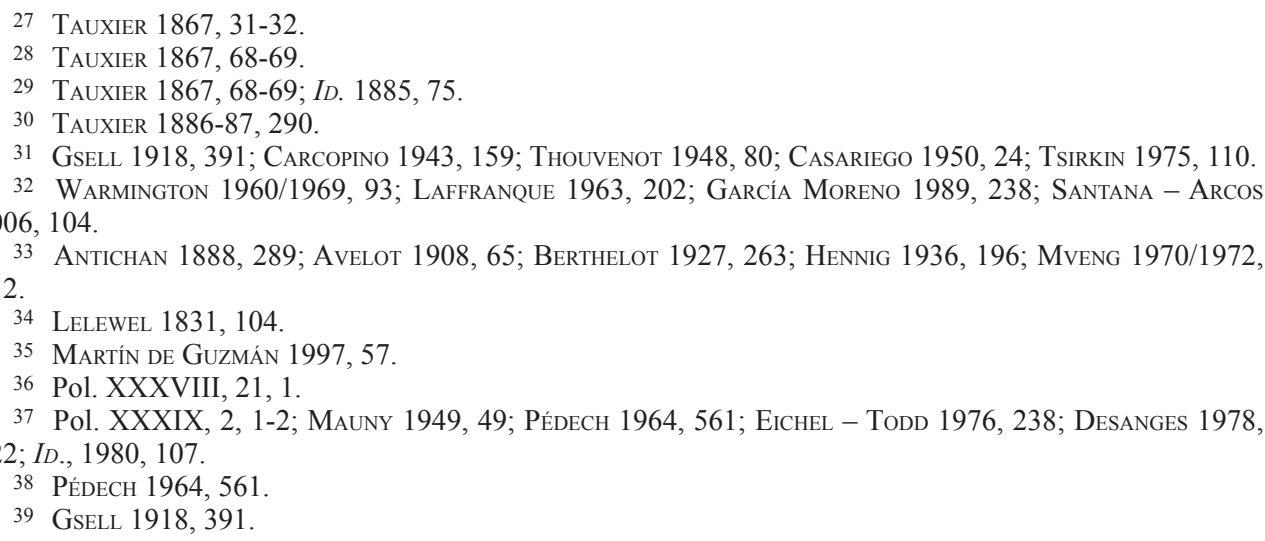




\section{Objetivos del periplo}

La razón del viaje está íntimamente ligada a su cronología, pues no es lo mismo que se realizara en pleno conflicto que una vez derrotada Cartago. Si se realizó en 147 a.C., podría ser importante conocer los puertos donde podían reclutarse mercenarios que pudiesen apoyar en algún momento a Cartago, o los puntos donde se obtenían elefantes africanos para el ejército cartaginés. Por ejemplo, Silio Itálico menciona la presencia en el ejército de Aníbal, durante la Segunda Guerra Púnica, de gétulos autololes, elogiándolos por su rapidez, ${ }^{40} \mathrm{o}$ de los baniures, que usaban lanzas endurecidas al fuego, sin punta de hierro. ${ }^{41}$

En esta línea, Gossellin ${ }^{42}$ sugiere que la razón de la expedición sería destruir la ciudad de Lixus, apoyándose en el texto de Plinio ${ }^{43}$ donde indica que "esta ciudad era muy poderosa e incluso mayor que Carthago Magna", y así asegurarse el control del resto de la costa atlántica.

Si el viaje fue una vez producida la caída de Cartago en 146 a.C., se ha sugerido por Eichel y Todd ${ }^{44}$ que pudo influir evitar una posible oposición militar de estas regiones a Roma.

Sin embargo, Roma controlaba el sur de la Península Ibérica desde el final de la Segunda Guerra Púnica, por lo que no es presumible una resistencia significativa en las regiones más occidentales de la monarquía mauretana o más concretamente en las antiguas fundaciones fenicias que fueron después aliadas de Cartago. Por ello, nos parece más realista que el objetivo fuese dar a conocer de primera mano, por parte romana, que Cartago había sido destruida y que estas regiones pasaban a estar en la órbita política de Roma, que es la explicación que creemos más razonable, sin objetivos militares, sino informativos y exploratorios.

Aunque los datos cuantitativos parten de Gadir, donde la expedición debió hacer escala para incorporar pilotos y avituallarse, el recorrido por la costa mediterránea norteafricana serviría también para dar a conocer la noticia a algunas de las antiguas colonias fenicias y de Cartago.

Otros autores consideran que ya desde el principio hubo motivaciones económicas de tipo comercial, por el interés de los mercaderes de Roma de romper el predominio comercial gaditano en las costas atlánticas norteafricanas. ${ }^{45}$ Este aspecto quizás entonces fuese prematuro pues Gadir era una ciudad aliada y amiga de Roma y sería más lógico que entonces el viaje se organizase al menos al año siguiente, en vez de inmediatamente después de una guerra de aniquilación.

Más énfasis se ha puesto en un conocimiento de la ruta marítima de abastecimiento de oro en polvo norteafricano, ${ }^{46}$ tratando de alcanzar la región de Bambouk, distrito

40 Sil. Ital. Pun., II, 63; III, 306. Se han consultado las ediciones de Akal Clásica (nº 77, de 2005, traducción de J. Villalba Álvarez) y The Loeb Classical Library (nº 277 y 278, de 1961, a cargo de J. D. Duff).

41 Sil. Ital. Pun., III, 303.

42 Gossellin 1797-98, 107.

43 Plin. N.H., V, 4.

44 EICHEL - TODD 1976, 238.

45 TSIRKIN 1975; ID. 1985, 254.

46 Simões de Paula 1946, 195. 
aurífero situado entre el río Senegal y su afluente el río Falemé. ${ }^{47}$ En este caso cabe plantearse que difícilmente podía realizarse con un tiempo limitado de 5 meses el 146 a.C., y menos aún en pleno asedio el 147 a.C., ya que requería la exploración de regiones bastante meridionales, que probablemente los gaditanos ya visitaron regularmente desde la derrota de Cartago en la Segunda Guerra Púnica.

Un argumento lógico que ha planteado $\mathrm{Schmitt}^{48}$ es que, antes de la destrucción de Cartago, los romanos debieron inspeccionar cuidadosamente el templo de Kronos, el último punto de resistencia de la ciudad, ${ }^{49}$ y pudieron allí conocer la inscripción que informaba de la expedición de Hannón - antes de proceder a la demolición del templo- y así conocer la existencia de la isla de Kérne o del volcán Theôn Óchema.

\section{Punto de partida, miembros de la expedición y flota}

Si se presupone que el viaje de Polibio fue inmediatamente después de la caída de Cartago, lógicamente el punto de partida debía ser el propio puerto de Cartago. No obstante, no falta algún autor que propone como punto de salida a las ciudades de Gadir o Carthago Nova ${ }^{50}$ o simplemente que se hizo escala en Gadir ${ }^{51}$ Este argumento es rechazado por Desanges, ${ }^{52}$ que no lo encuentra lógico, pues en Cartago o Útica habría marinos experimentados y, en caso de buscar intérpretes, Lixus sería un puerto más adecuado. Obviamente, la mención de una distancia de 2 días y noches de navegación entre el Estrecho Gaditano y Lixus no puede ser partiendo desde Cabo Espartel o Tingi, sino desde la propia Gadir, que es un punto lógico de aprovisionamiento y búsqueda de pilotos e intérpretes.

Se ha planteado que Polibio estuvo acompañado por Panecio -Panaitios, Panaetius - de Rodas, ${ }^{53}$ apoyándose en un papiro de Herculano, pues ambos creían que la zona tórrida estaba habitada. ${ }^{54}$ El papiro menciona que Panecio fue enviado por un general a una expedición científica con una flota de 7 barcos..$^{55}$ Es difícil que fueran necesarias siete embarcaciones militares para una expedición exclusivamente científica, salvo que esperasen encontrar resistencia armada.

Se apoya también en un texto de Veleyo Patérculo: "Escipión fue hombre tan acostumbrado a los estudios intelectuales, y tan admirador y promotor de toda erudición, que tuvo a su lado, tanto en su casa como en campaña, a talentos destacadísimos como Polibio y Panecio". ${ }^{56}$

47 Gautier 1942, 48; Thouvenot 1956, 91.

48 SchmitT 1968, 377.

49 App. Lib., 130. Se ha consultado la edición de la Biblioteca Clásica Gredos (nº 34, de 1989, con traducción de A. Sánchez Royo).

50 CAsariego 1949, 62; ID. 1950, 24.

51 PÉDECH 1955, 327.

52 Desanges 1980, 111.

53 CiCHORIUS 1908, 220-221.

54 KeYser 1993, 156, n. 57-58.

55 Cichorius 1908, 221.

56 Vel. Pat. I, 13, 3, (traducción de A. Ma Canto). Para la obra de este autor se han consultado las ediciones de la Biblioteca Clásica Gredos (n 284, de 2011, traducción de M $^{\mathrm{a}}$ A. Sánchez Manzano) y The Loeb Classical 
Otro de los escritores que se ha supuesto participó en la expedición fue Jenofonte de Lámpsaco, dentro de una tripulación mayoritaria de griegos de la costa egea de Anatolia. ${ }^{57}$ Jenofonte menciona la presencia de las pieles de las Górgades ofrendadas por Hannón en el templo de Juno de Cartago, ${ }^{58}$ por lo que Schmitt considera que debió estar presente en la caída de Cartago y después en la expedición de Polibio, ${ }^{59} \mathrm{y}$ durante el asedio pudo observar "la piel de las dos [mujeres de las islas Górgades]", la cual "se conservó hasta la fecha de la destrucción de Cartago". ${ }^{60}$

Esta línea ya la inició Gossellin ${ }^{61}$ cuando comentaba que una vez capturada la ciudad, Polibio se valdría para su expedición de pilotos cartagineses y de documentación donde podría indicarse la ruta que había seguido Hannón, o simplemente, por haberse ya divulgado el relato del viaje de Hannón. ${ }^{62}$ Finalmente, también se ha sugerido por Laffranque ${ }^{63}$ que el propio Escipión pudo haber acompañado a Polibio en su viaje exploratorio, lo que no está demostrado, pero sería interesante en caso de propugnarse una cronología previa a su acceso al mando el 147 a.C., entre 149 y 148 a.C.

\section{Trayecto}

En general, como en toda la discusión sobre los periplos atlánticos, hay una profunda división entre los autores que propugnan un recorrido corto, es decir con un límite en torno al Cabo Juby, con prolongaciones máximas hasta Seguia el-Hamra o Río de Oro, y aquellos que plantean que se alcanzó la costa del Senegal y del Camerún por la mención del río Banbotum y de la montaña del Theôn Óchema. En este aspecto también influye la cronología del viaje, pues no es lo mismo que el viaje se tuviera que hacer en un máximo de 5 meses, el 146 a.C., que otro año donde pudo haber mayor margen temporal.

El trayecto más corto es planteado por Blázquez y Delgado-Aguilera ${ }^{64}$ que asocia el promontorio del Sol con Cabo Espartel, pues considera que el texto no sigue un orden y sitúa el Theôn Óchema en los montes al suroeste de Mogador. Se acepte o no su ubicación, la cuestión es que localiza en Mogador el límite sur del viaje de Polibio, como también lo hacen otros autores que ubican Kérne en Mogador, ${ }^{65}$ quizás por ser el último topónimo citado junto al nombre de Polibio.

Por otra parte, Blázquez y Delgado-Aguilera ${ }^{66}$ plantea serias dudas a un trayecto que superase los ríos Sububa [Sebou] y Salat [Salé, actual Bou Regreg] y el puerto

\footnotetext{
Library ( $\mathrm{n}^{\circ} 152$, de 1967, a cargo de F. W. Shipley).

57 Sснмітт 1968, 376-377.

58 Plin. N.H., VI, 200; Sol. 56, 10-12. (se ha empleado la edición de la Biblioteca Clásica Gredos: $n^{\circ} 291$, de 2001, traducción de F. J. Fernández Nieto).

59 Sснмітт 1968, 378.

60 Sol. 56, 12.

61 Gossellin 1797-1798, 107.

62 Thouvenot $1948,91$.

63 LAFFranQue 1963, 202.

64 BlázQuez y Delgado-Aguilera 1921, 413-414, 488.

65 Tsirkin 1975, 112.

66 Blázquez y Delgado-Aguilera 1921, 494.
} 
de Rutubis, que ubica hacia Casablanca. Esta idea también subyace en Tauxier, ${ }^{67}$ pues señala que Polibio sólo alcanzó hasta el río Anatis, que sitúa en el río Oum er-Rbia, probablemente porque a partir de este punto no se indican distancias.

Los partidarios de un trayecto medio, que arrancan del trabajo de Gossellin, ${ }^{68}$ consideran que se alcanzó el sur de Marruecos o incluso el norte del Sahara y tienen sus anclajes principales en la identificación del río Masathat con el río Massa y en particular del río Darat con el río Drâa.

Especial énfasis se ha prestado al emplazamiento de Kérne, más que por quienes tratan el Periplo de Hannón que entre los que han estudiado el Periplo de Polibio. Para los partidarios de un trayecto corto, la ubicación preferida de Kérne oscila entre la desembocadura del río Sebou y el islote de Mogador. La primera propuesta fue situarla en la isla de Samta María des Portugais-Djezira Sidi Youssef, a $23 \mathrm{~km}$ por encima de Mehdia, en la desembocadura del río Sebou ${ }^{69} \mathrm{Su}$ argumentación fue retomada por Lipinski, ${ }^{70}$ situándola primero genéricamente en el estuario del río Sebou, y posteriormente más en detalle en la Merja de Beni Ahsen, donde desembocan los ríos Beht y Rom. ${ }^{71}$

La opción alternativa es el islote de Mogador desde su propuesta por Mauny, ${ }^{72}$ que sigue gozando de numerosos partidarios ${ }^{73}$ y que nos parece la más apropiada por los datos arqueológicos actualmente disponibles.

No obstante, un grupo importante de autores, partidarios de un trayecto largo, optan por ubicaciones mucho más meridionales como el Puerto Pesquero de El Aaiún, ${ }^{74}$ la isla de Herné de Río de Oro-Villa Cisneros, ${ }^{75}$ la isla de la bahía de Arguin en Mauritania ${ }^{76}$ o una isla en el río Senegal. ${ }^{77}$

Las discrepancias se agudizan en la identificación del río Banbotum, el cual se ha asociado con el río Massa, ${ }^{78}$ el río Nun o Noun ${ }^{79}$ o el río Seguia el-Hamra. ${ }^{80}$

67 TAUXIER 1867,$32 ;$ ID. 1885, 75.

68 Gossellin 1797-98.

69 ReBuffat 1985-1986, 261-262; ID. 1988, 199.

70 LIPINSKI 1995, 1332.

71 LIPINSKI 2004, 459.

72 Mauny 1949, 57.

73 Jodin 1988, 88; EuZENNAT 1990-92, 223; ID. 1994, 573, 576; Gozalbes 1993a, 19; ID. 1993b, 14-15; ID. 2000, 27; Culican 1991, 545; López Pardo 1991, 62; Desanges 2001, 33; Medas 2006, 21, 35; López Pardo - Mederos 2008, 91; González Ponce 2010, 767.

74 Díaz del Río 2005, 157-160, 175.

75 BaLBín et alii $1995 \mathrm{~b}, 46$.

76 Huss 1990/1993, 47; GonZÁlez Antón et alii 1995, 11; Roller 2006, 120.

77 Jorge 1996, 69; Millán 1998, 158; CunLIFFe 2001, 89.

78 Mauny 1949, 60.

79 Gossellin 1797-98, 117; WalcKenaer 1821, 362; Mauny 1970a, 103; ID. 1970b, 80; ID. 1978, 299.

80 Gsell 1928, 298; Pédech 1955, 329; ID. 1964, 560 n. 264; Desanges 1978, 141; ID. 1980, 117-118; LóPEZ PARDO 2000, 84. 
Un trayecto largo es defendido por Müller ${ }^{81}$ o Hennig, ${ }^{82}$ quienes asocian el río $D a-$ rat con el Río de Oro, y aún más por quienes lo atribuyen al río Senegal, a partir del trabajo de Quatremère, ${ }^{83}$ río que los Oulofs del Senegal denominan Ndar. ${ }^{84}$

Aceptado que se alcanzaron latitudes tan meridionales, un paso adelante es el emplazamiento del río Banbotum, al cual muchos de los citados autores sitúan en el río Senegal desde Müller, ${ }^{85}$ mientras que los que optan por el Darat en Río de Oro siguen hacia el Sur hasta el río Gambia ${ }^{86}$ o entre el río Gambia y el Casamance del sur de Senegal. ${ }^{87}$

Finalmente, el volcán Theôn Óchema se ha situado entre monte Kakoulima en Guinea Conakry, ${ }^{88}$ al noreste de Liberia, ${ }^{89}$ o principalmente en el monte Camerún, de $4.040 \mathrm{~m}$ y aún activo en el año 2012, siendo la altura principal desde el Alto Atlas, que apenas lo supera con 4.167 y $4.088 \mathrm{~m} .{ }^{90}$ La mención del monte Sagres parece referirse a Punta Sagres en Guinea Ecuatorial. ${ }^{91}$

Según algunos autores partidarios de rutas muy meridionales sería inconcebible que Polibio y Panecio, siendo espíritus curiosos y racionalistas, a la cabeza de una escuadra, virasen de regreso una vez alcanzado el Cabo Juby. ${ }^{92}$ Sin embargo, a veces se olvida una frase del propio Polibio: "los peligros y fatigas que nos acaecieron en un viaje por Libia (...) y el mar que circunda estos países por el lado exterior". ${ }^{93}$

La relación de los datos de Plinio a partir de 1 passus equivalente a 5 pies de $c a$. $0.293 \mathrm{~m}$, esto es, $1 \mathrm{~m}$ y $46.6 \mathrm{~cm}$, hacen suponer que sus mil pasos, mille passuum, o milla romana, corresponden a 8 estadios de $185 \mathrm{~m}$ cada uno o $1478.5 \mathrm{~m}$, aunque según Gsell ${ }^{94}$ el estadio de Polibio debía ser de $177.6 \mathrm{~m}$, y mil pasos serían 1420.8 $\mathrm{m}$, utilizando el estadio griego. Sin embargo, Desanges ${ }^{95}$ no cree necesario que las medidas originariamente estuvieran en estadios, sino en días de navegación, como sería lógico en un periplo.

Una de las aportaciones más interesantes ha sido mostrar que tres de las medidas que se aportan corresponden a días de navegación, pues son múltiplos de 56 que po-

\footnotetext{
81 MÜLLER 1855, XXXI.

82 HENNIG 1936, 196-197.

83 Quatremère 1857, 262; Berlioux 1884, 104; Antichan 1888, 294; Guarner 1932, 167.

84 Avelot 1908, 44.

85 Müller 1855, xxxi; Bunbury 1879, 325; Tozer 1891, 106; Cary - Warmington 1929, 52; Hennig 1936, 196; Gautier 1942, 49; Carcopino 1943, 142, 159; Simões de Paula 1946, 163, 195; Thouvenot 1956, 91; PicARD - PicArd 1958, 235; Warmington 1960/1969, 92-93; Ferguson 1969, 9; Eichel - Todd 1976, 240, 242; RAMIN 1976, 57 n. 255; DiLKe 1985, 48.

86 Quatremère 1857, 262; Berlioux 1884, 61, 82, 105; Antichan 1888, 297; Berthelot 1927, 266; Guarner 1932, 167; GatTeFossé 1932, 133.

87 SANTANA et alii, 2002, 154.

88 Berthelot 1927, 266.

89 Berlioux 1884, 105.

90 Antichan 1888, 295, 299; Berthelot 1927, 200; Thouvenot 1948, 91; Santana - Arcos 2002, 51; 2006, 104; SANTANA et alii 2002, 154.

91 MÜLler 1855, XXXI.

92 Thouvenot 1956, 91.

93 Pol. III, 59, 7.

94 Gsell 1918, 392, n. 5.

95 Desanges 1978, 127.
} 
drían corresponder a una jornada de navegación, ${ }^{96}$ argumento retomado por Pédech, ${ }^{97}$ por lo que entre Gadir y la ciudad de Lixus habría 112.000 pasos [56 millas -miles de pasos o milia passuum - x 2 días y noches], $168 \mathrm{~km}$. Entre la ciudad de Lixus y el puerto de Rutubis habría 224.000 pasos [56 x 4 días y noches], $336 \mathrm{~km}$. La tercera medida es más compleja pues se habla de un golfo de 616.000 pasos [56 x 11 días y noches], $924 \mathrm{~km}$, que iría desde Cabo Aguer, Ger o Ghir hasta el promontorio Hesperu Ceras o Cabo Juby, cuya distancia luego se señala es de diez días y diez noches, lo que resulta casi concordante con los datos citados.

Esto supondría que habría una medida que no se aporta, entre el puerto de Rutubis y el inicio del gran golfo que situamos en el Cabo Aguer o Ghir. No obstante, hay autores como Pédech ${ }^{98}$ que piensan que esta tercera medida no arrancaría desde Cabo Aguer, como inicio del golfo, sino a partir del puerto de Rutubis, que sitúa en Cabo Blanco junto a Mazagán, con lo que el recorrido total hacia el Sur sería sólo de 17 días.

Si tenemos en cuenta que Plinio, en otro pasaje, extracta nueva información de Polibio que no está incluida en los dos párrafos principales, es posible pensar que la descripción era más extensa y falta información de la zona central, junto al Atlas, de la cual no tenemos medidas. En concreto, menciona que la isla de Kérne, presumiblemente Mogador ya que es el único islote que existe, está "situada en el extremo de Mauritania, frente al Monte Atlas, dista de tierra firme ocho estadios". ${ }^{99}$

Más problemas aún crean los datos del periplo de Polibio que toman como punto de referencia la montaña del Atlas, que parecen estar orientados en dirección SurNorte, así señala 496.000 pasos, leído como $490.000,735 \mathrm{~km}$, por Santana et alii, ${ }^{100}$ hasta el río Anatis, y 205.000 pasos, $307.5 \mathrm{~km}$, desde el río Anatis hasta Lixus, ${ }^{101}$ pues no pueden convertirse a estas jornadas de navegación de 56 millas por día u $82 \mathrm{~km}$.

Thouvenot ${ }^{102}$ encuentra incomprensible la medida de 496.000 pasos, $745 \mathrm{~km}$, entre el Atlas, que sitúa en Cabo Aguer, y el río Anatis, sugiriendo que debe tratarse de una medida entre Ceuta -inicio del estrecho- y Cabo Aguer o bien entre Ceuta y Mogador. Si se toma como una medida desde el Sur, el Anatis sería el Oum er-Rbia desde Cabo Juby, y si se identifica con el río Tensif, se mediría desde el Cabo Bojador. ${ }^{103} \mathrm{La}$ distancia de 205.000 pasos, 305 km, considera es la existente entre el Anatis o Oum er-Rbia y el río Lucos. ${ }^{104}$

Una solución diferente, efectuando correcciones a las cifras, es propuesta por Klotz ${ }^{105}$ quien sugiere que los 496.000 pasos deben ser 896.000, DCCCLXXXXVI, y entonces serían 56 millas x 16 días y noches de navegación. Otra alternativa

\footnotetext{
96 KLOTZ 1906, 15.

97 PÉDECH 1955, 321.

98 PÉDECH 1955, 328.

99 Plin. N.H., VI, 199.

100 SANTANA et alii 2002, 133, 150-151.

101 Plin. N.H., V, 9.

102 Thouvenot 1939, 116; ID. 1956, 89.

103 Thouvenot $1956,89$.

104 Thouvenot 1956, 89.

105 KLotz 1906, 15.
} 
es la ofrecida por Desanges, ${ }^{106}$ quien considera que hay un error de lectura en 496, CCCCXCVI, que también podría haber sido escrito como CCCCLXXXXVI (según comunicación personal de A. M. Canto), proponiendo Desanges que debía haberse escrito 477, CCCCLXXVII, 56 x 8.5 días o 476.000 pasos.

En los cálculos efectuados por Eichel y Todd, ${ }^{107}$ estiman que habrían sido necesarios 14 días para hacer el recorrido hasta el río Drâa, fondeando cerca de la costa durante las noches y el doble de tiempo para regresar, unos 28 días, sumando 42 días en total. No consideran probable una navegación hasta el Senegal, donde sitúan el río Banbotum, que exigiría 20 días adicionales navegando desde el río Drâa en el trayecto de ida, y 40 en el de regreso, 60 en total, pues implicaría un viaje de 102 días, algo más de tres meses, y después Polibio tendría que haber explorado la costa atlántica de la Península Ibérica y la Galia.

La estimación de Pédech ${ }^{108}$ propone un trayecto descendente de 17 días, a 56 millas por día u 82 km, hasta Hespéru Keras o Cabo Juby y el río Banbotum o Seguia el-Hamra, otros 17 días para regresar, 34 días, más 13 días de ida entre Cartago y las Columnas de Hércules, que suman 26 al volver, en total 60 días, lo que daría 2 meses de viaje. Desanges ${ }^{109}$ cree que el regreso sería algo más lento y lo alarga hasta 2.5 meses de viaje, a unos $45 \mathrm{~km}$ diarios, entre mayo y agosto. Así, por ejemplo, en el golfo hespérico de 616.000 pasos, unos $400 \mathrm{~km}$, considera que por ser una costa particularmente inhóspita la velocidad sería de unas 30 millas diarias. ${ }^{110}$ En cambio, para Mauny ${ }^{111}$ la velocidad sería superior, unos $100 \mathrm{~km}$ por el día y $85 \mathrm{~km}$ por la noche, en función de los datos que proporciona para el trayecto en el Golfo del Hespéru Keras.

\section{Estudio crítico}

Para valorar este complejo periplo lo primero que debe precisarse es si se trata de la información proporcionada por una fuente o por dos, que es la opción que preferimos por la reduplicación de topónimos en la mención de los ríos y pobladores de los ríos Salsum y Darat en la parte final del viaje.

En segundo lugar, deben definirse cuáles fueron las fuentes. Es obvia la autoría de Polibio en la segunda parte del texto, ${ }^{112}$ y para nosotros en el principio, ${ }^{113}$ la segunda fuente debe ser Juba II, que envió una exploración costera a inicios de su reinado en la Mauretania, a partir del 25 a.C., y no hay constancia que así lo hiciera Agripa. Ello no descarta que algunos datos estén filtrados por los Comentarios de Agripa, pero es importante señalar que la expedición de Juba II fue un periplo que usó probablemente

\footnotetext{
106 Desanges 1978, 132; ID. 1980, 109.

107 Eichel - Todd 1976, 242-243.

108 PÉDECH 1955, 332.

109 Desanges 1978, 143 y 147.

110 Desanges 1980, 120.

111 Mauny 1949, 61.

112 Plin. N.H., V, 10.

113 Plin. N.H., V, 9.
} 
embarcaciones y tripulaciones gaditanas que comerciaban por las costas atlánticas norteafricanas.

Si se acepta esta propuesta, completamos buena parte del trayecto descendente de la expedición de Juba II, que estaba bien determinada en la exploración a las Islas Afortunadas por conservarse la mención de su nombre en Plinio, ${ }^{114}$ pero era incomprensible que faltase cualquier dato de su recorrido costero norteafricano.

Además, es la opción más lógica si observamos la toponimia fenicio-púnica del periplo. ${ }^{115}$ Ya el propio Mauny, aunque la atribuía a Agripa, advertía que esta fuente, por su toponimia púnica, recogía "las escalas de comercio lixita y gaditano". ${ }^{116}$

Se trató de un viaje eminentemente costero, donde se menciona la ciudad de Lixus, no el río, y dos poblaciones más al Sur, la ciudad del promontorio de Mulelacha y el puerto de Rutubis [Azemmour], en la desembocadura del río Oum er-Rbia, si bien no se cita el río ni su nombre, y sí previamente los dos principales ríos, Sububa [Sebou] y Salat [Salé, actual Bou Regreg], antes del Promontorio del Sol [Cabo Cantín], límite del territorio conocido.

Las medidas aportadas son sólo dos, las justas, del Estrecho Gaditano [Gadir-Septem] hasta Lixus, 112.000 pasos, 56 millas x 2 días y noches, y del puerto de Rutubis [Azemmour] hasta Lixus, 224.000 pasos, 56 x 4 días y noches.

En esta costa, las distancias entre los tres principales ríos más septentrionales están recogidas por Plinio, que indica 50.000 pasos entre la ciudad de Lixus en el río Lucus y el Sebou, y otros 50.000 pasos entre el Sebou y la ciudad y río de Sala, ${ }^{117}$ que indican trayectos de casi un día de navegación, en concreto 0.9 , a la velocidad de 56 millas.

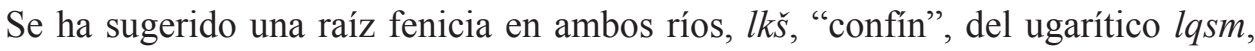
$l k s m^{118}$ y $s b b$, "dar vuelta, girar". ${ }^{119}$ No obstante, como nos señala E. Lipinski (comentario personal), realmente las raíces son $q s m, k s m$ o $k \check{s}$, pues hay que leerlas sin la preposición $l$. Una posible conexión sería Lakish en Israel, $l k s ̌$, pero desconocemos el valor que tenía el nombre de esta ciudad.

La población de Mulelacha es casi unánimemente atribuida a Moulay Bou Selham, o Vieja Mamora, ${ }^{120}$ que es más un entorno lagunar. Sin embargo, debemos tener en cuenta que la única ciudad que menciona Ptolomeo es Sala y quizás al sólo citar el nombre del promontorio en la desembocadura del río Salé, realmente está ocultando un antiguo nombre de Sala.

El primer puerto que encontramos en la cartografía de Ptolomeo (IV, 5,1$)$ es el de Rusibis, a $6^{\circ} 40^{\prime}$ longitud Este y $32^{\circ} 30^{\prime}$ latitud Norte y debe tratarse del denominado puerto de Rutubis, el primero que menciona Juba II y situamos en Azemmour.

114 Plin. N.H., VI, 32, 202-205.

115 LiPINSKI 2004; LÓPEZ PARDo 2009.

116 Mauny 1949, 54.

117 Plin. N.H., V, 5.

118 LÓPEZ PARDO 2004, 86; ID. 2009, 26.

119 López PARDo 2004, 91; ID. 2009, 42.

120 Müller 1855, xxxi; Tissot 1877, 124-125; Hennig 1936, 196; Thouvenot 1939, 117; ID. 1948, 88; Mauny 1949, 54, n. 2; Pédech 1955, 328; Desanges 1980, 111-112; Ponsich 1982, 439; Lipinski 2004, 458; Gozalbes 2011, 164. 
Así pues, en su parte inicial, el periplo de Juba II lo que recoge son las tres ciudades principales de la costa, seguramente todas fundaciones fenicias, Lixus, Sala y Rutubis, y los tres principales ríos, básicamente porque se trataba de una región conocida integrada en su reino y no era el objetivo de la expedición exploratoria. En época fenicia el objetivo principal fue el control de los principales ríos que drenaban hacia la costa los recursos del interior.

Sobrepasado el Promontorio del Sol, se entraba en el territorio de los gétulos autololes, mencionándose una única localidad, el puerto de Rhysaddir, Rs addir, cabo prominente o Cabo de las - montañas- imponentes [Mogador y Cabo [Baal] Hadid algo más al Sur], y tres cursos fluviales, el río Cuoseno [Ksob, junto a Mogador], el río Masathat [Massa] y el río Darat [Drâa, Dr, río imponente], además de dos pueblos costeros próximos a ríos, los selatitos [del río Salsum, Sous] y los masatos [del río Massa].

Si la montaña Helios es el Cabo Cantín, a $6^{\circ} 45^{\prime}$ longitud Este y $31^{\circ} 15^{\prime}$ latitud Norte en la cartografía de Ptolomeo, a continuación viene el segundo puerto, Mysogara o Mysocaras, que debe tratarse del puerto de Rhysaddir en Juba II, actual Mogador, a $7^{\circ} 20^{\prime}$ longitud Este y $30^{\circ}$ latitud Norte y junto a éste, el río Phout/Phut, que debe ser del río Cuoseno de Juba II, actual Ksob, junto a Mogador, a $7^{\circ}$ 30' longitud Este y $30^{\circ} 30^{\prime}$ latitud Norte.

No hay distancias para toda la región del Atlas o los Montes Claros, cuyo principal acceso al interior era Mogador, aprovechando el cauce del río Ksob. Pero justo en el inicio del párrafo siguiente, el cual se atribuye a Polibio, menciona una distancia que es divisible por 56 millas y debe proceder también de Juba II, para el golfo desde la región costera visible del Atlas o Monte Braca, en el entorno de Cabo de Aguer o Ger, actualmente Ghir, que denomina Surrentium, golfo que alcanzaría hasta el Hesperu Ceras o Cabo Juby con 616.000 pasos, 56 x 11 días y noches, a lo largo de $924 \mathrm{~km}$.

$\mathrm{Si}$ intentamos reconocer estos tres puntos en la cartografía de Ptolomeo vemos que después del promontorio Oussadion-Ussadium-Vasadium, se menciona SourigaSuriga, sin especificar qué es, el cual presenta también la raíz $S r$, "roca", presente en Sur, la ciudad de Tiro en fenicio o Surru en acadio, actualmente conocida por su nombre griego, Týros. Su significado sería, según Lipinski, ${ }^{121}$ Sur higa, "la roca que resuena", por el choque de las olas del mar, y se podría asociar con Surrentium. Respecto al río, debe tratarse del cauce principal al final de esta región montañosa. Por ello, el Salsum de Polibio debe ser el que Ptolomeo pone como río Sala, a $8^{\circ} 20^{\prime}$ longitud Este y $27^{\circ} 20^{\prime}$ latitud Norte, y se vincula a las tribus de los selatitos que menciona Juba II, que creemos asociable con el actual río Sous.

Debe tenerse en cuenta que en el periplo enviado por Juba II, aunque en el trayecto de bajada hacia el Sur se iría costeando hasta el río Drâa por su objetivo exploratorio, para continuar atravesando de Este a Oeste las Islas Canarias, ${ }^{122}$ en la ruta de regreso se navegaría en altura en dirección hacia el Cabo Aguer, o más probablemente hacia el puerto más meridional que menciona, Rhysaddir, el islote de Mogador, por lo que

121 LIPINSKI 2004, 467.

122 Plin. N.H., VI, 202-205. 
las Islas Canarias orientales fueron situadas frente a esta región, "descubiertas por Juba frente a los autololes, en las que había mandado producir púrpura getúlica". ${ }^{123}$

El viaje exploratorio conservado supondría 17 días y 952.000 pasos entre Gadir o Septem Fratres y el río Darat, pero como no tenemos distancia para el trayecto entre Rutubis [Azemmour] y el cabo Surrentium [Aguer], podemos sumar otros 224.000 pasos, 56 x 4 días y noches, que totalizan 21 días y 1.176.000 pasos.

Esta distancia es importante porque si la comparamos con el ancho máximo que Agripa señala para la Etiopía, medido a partir del Delta hasta el Alto Egipto y alcanzar el "Océano de Etiopía" -indicativo del conocimiento de África a finales del siglo I a.C. por Roma-, suma 1.296 .000 pasos, ${ }^{124}$ es decir 23 días de navegación de exploración, sólo 2 días más. Además, puede obtenerse al menos un día con el trayecto del río Darat o el Banbotum hasta el Hespéru Keras, o actual Cabo Juby, o sumando algo más al trayecto costero en la zona del Atlas. En cambio, el territorio que debía controlar Juba II más o menos directamente era la Mauretania útil, que se cifraba en 467.000 pasos, ${ }^{125}$ es decir, 8.3 días de navegación.

El segundo periplo, con los datos de Polibio, es de más compleja interpretación por conservarse parcialmente. Sólo hay mención expresa de Polibio en relación con tres topónimos: Lixus, el río Anatis y la isla de Kérne. Respecto a estos tres, el orden de las distancias está invertido en los dos primeros, poniéndolos con orientación ascendente de Sur a Norte, y no se especifica una distancia para alcanzar Kérne.

Por otra parte, el texto utiliza una toponimia más antigua que la del periplo de Juba II, con referencias que se retrotraen hasta el periplo de Hannón, caso de Kérne, Banbotum o Theôn Óchema, lo que podría sugerir que se están utilizando nombres de los que se tuvieron conocimiento al acceder al periplo de Hannón en Cartago, bien por la inscripción en el templo de Kronos como apunta Schmitt, ${ }^{126}$ bien por documentación en sus bibliotecas como sugería Gossellin. ${ }^{127}$ Otro aspecto que podría apuntarlo es la mención de poblaciones del interior, y que en un periplo de exploración costero efectuado con cierta rapidez tampoco resultan muy lógicas. En este sentido, entre los pueblos que se mencionan están los farusios o Pharusii, poblaciones del interior que podían transportar oro en sus carros. ${ }^{128}$ Por otra parte, es posible que Polibio no se detuviera a realizar escalas prolongadas por los problemas que menciona, "los peligros y fatigas que nos acaecieron en un viaje por Libia (...) y el mar que circunda estos países por el lado exterior", ${ }^{129}$ que pudieron afectar a alguna de sus embarca-

123 Plin. N.H., VI, 201.

124 Plin. N.H., VI, 196.

125 Plin. N.H., V, 21.

126 SChMiтt 1968, 376-377.

127 Gossellin 1797-1798, 107.

128 Pomp. Mel. III, 10, 103; Str. XVII, 3, 7. Para la obra de Pomponio Mela se han empleado las ediciones de Fontes Hispaniae Antiquae (vol. VII, 1-12, 101-112, de 1987, editado por V. Bejarano), Les Belles Lettres (1988, editado por A. Silberman) y la Universidad de Murcia (de 1989, traducción de C. Guzmán Arias). Para la Geografía de Estrabón las ediciones de la Biblioteca Clásica Gredos (nº 159, libros I-II, de 1991, con traducción de J. García Blanco, y n ${ }^{\circ} 288$, libros V-VII, de 2001, con traducción de J. Vela y J. Gracia) y The Loeb Classical Library ( ${ }^{\circ} 49$, vol. I, libros I-II, de 1917/1989; nº 182, vol. III, libros VI-VII, de 1924; y nº 267, vol. VIII, libro XVII, de 1932/1982; todos a cargo de H. L. Jones).

129 Pol. III, 59, 7-8. 
ciones, como también le sucedió a Eudoxo de Cícico. ${ }^{130}$ En todo caso, parece que el texto elaborado por Polibio no sólo utilizaba información propia, sino también otras disponibles en fuentes escritas previas.

La información estrictamente toponímica es muy escasa, una ciudad, Lixus, la isla de Kérne, y tres ríos, Anatis, Salsum-Palsum y Banbotum. A partir de las menciones de los gétulos daras o de los etíopes daratitas, si es que el dato procede de Polibio, podemos presumir que conoce también el río Darat, pero creemos que son datos de Juba II.

Hay dos frases finales que, como se ha indicado desde Gossellin, ${ }^{131}$ resultan muy vagas, "una serie ininterrumpida de montes hasta el que llamaremos Theôn Óchema", que sería entonces un monte costero, más la mención final del Hespéru Keras.

Las distancias indicadas tampoco ayudan mucho. Al inicio no se especifica la separación entre el Estrecho Gaditano y Lixus. La primera que se menciona es una entre el río Anatis y la ciudad de Lixus, de 205.000 pasos. Si por el periplo de Juba II sabemos que el puerto de Rutubis estaba a 224.000 pasos de Lixus y 4 días de navegación, implica que se trataría de un río a 19.000 pasos al norte del Anatis, que si lo situamos en el río Oum er-Rbia resulta difícil de encajar. Tampoco se adecua bien si situásemos el puerto de Rutubis en Casablanca o junto al islote de Fedala y el Anatis en el río Salé, actual Bou Regreg. Por otra parte, un dato en Solino podría contradecir esta información de Polibio e indica que "el Atlas -no el Anatis- dista de Lix 205.000 pasos". ${ }^{132}$ Podría implicar que se presupone que la mención del Atlas implica la región al Sur de Rutubis, donde el río Oum er-Rbia actuaba de frontera, y era el inicio de las poblaciones gétulas de los autololes. Las diferentes medidas, 224.000 en Juba II, 4 días, y 205.000 en Polibio, 3 días y 2/3, tampoco son importantes porque 19.000 pasos son apenas un tercio menos de la distancia que se recorrería en un día, lo que podría explicarse por cualquier escala, mayor aproximación a la costa o contratiempo en la navegación.

Si observamos una de las referencias de Polibio, "desde esta montaña [Atlante] hasta el ocaso hay bosques llenos de las fieras que engendra África (...) hasta el río Anatis", 133 veremos que es sospechosamente parecida a un párrafo del periplo de Hannón, donde se menciona un gran río y el inicio del Atlas, "más hacia el interior habitaban etíopes poco hospitalarios que ocupaban un país repleto de fieras surcado por elevadas montañas [Atlas] desde las que afirman que fluye el Lixo", ${ }^{134}$ al sur de la cual empieza la verdadera exploración de Hannón, alcanzando después de 3 días de navegación desde este gran río la isla de Kérne.

El Anatis, a priori, podría tratarse del río Asana o Asama, a $6^{\circ} 15^{\prime}$ longitud Este y $32^{\circ}$ latitud Norte de la cartografía de Ptolomeo. Debe tenerse en cuenta que el nombre de este río, Asana, posible Oum er-Rbia, no es citado en el periplo de Juba II, pero previamente se cita el puerto de Rutubis, que también precede, a $6^{\circ} 40^{\prime}$ longitud

\footnotetext{
130 Mederos - Escribano 2004, 222-223.

131 Gossellin 1797-1798, 119.

132 Sol. 24, 11.

133 Plin. N.H., V, 9.

134 Hanno Peripl., 7.
} 
Este y $32^{\circ} 30^{\prime}$ latitud Norte, como puerto de Rusibis en Ptolomeo al río Asana y debe tratarse en ambos casos de Azemmour, donde aún no se ha localizado ocupación fenicia, pero es casi seguro que tuvo que haberla en el núcleo urbano o en su entorno inmediato, como puede apreciarse si se visita el sitio.

Una segunda medida de Polibio, entre la montaña Atlante y el río Anatis de 496.000 pasos, sí coincide con los datos de Solino, "entre el propio monte [Atlas] y el río Anatis", ${ }^{135}$ y nos señalaría un trayecto de 9 días, si seguimos el cálculo del periplo de Juba II, 56 millas x 8.9 días y noches. Lo lógico sería que el inicio del Atlas, que hemos situado al sur del río Oum er-Rbia, sea de nuevo el punto de referencia y lo que nos está señalando es un trayecto de 9 días hacia el Sur, hasta un río que denomina Anatis, que habitualmente se sitúa por todos los autores más al Norte, básicamente identificándolo con el propio río Oum er-Rbia desde Gossellin ${ }^{136}$ hasta Lipinski, ${ }^{137}$ aunque también hay propuestas para situarlo algo más al Sur, como el río Tensif. ${ }^{138}$ Serían unos 4 días para la región del Atlas y 5 días en el golfo meridional al sur de Cabo Aguer.

Al ser la región del inicio del Atlas el punto de sus referencias para Polibio, explica que al final del párrafo indique que entre Lixus y el Hespéru Keras o Cabo Juby, los dos extremos de su periplo, "en medio de ese espacio situó el Atlas".

Esto implicaría que la información de los ríos que nos proporciona Polibio es toda del sur de Marruecos, lo más lógico por ser la región más desconocida para los romanos, con los ríos Salsum-Palsum, Anatis y Banbotum. Si el Salsum lo asociamos con el Sous, y sus habitantes son los selatitos que citaba el periplo de Juba II, y el Banbotum con el río Aoueri, en Santa Cruz de Mar Pequeña, creemos que el Anatis debe tratarse de una denominación antigua del río Drâa, que por eso no es mencionado, antes que buscar otro río como el Massa, denominado Masathat por Juba II, o el Assaka, aunque ya debería coexistir ese nombre con el de río Darat, pues se citan los etíopes daratitas en la costa y los gétulos daras más al interior, pero esta denominación parece más moderna que Polibio, al citarse a poblaciones getulas. Por tanto, Anatis sería el nombre del Drâa en Polibio y Darat, getulos daras y etíopes daratitas, todos serían nombres procedentes de Juba II.

Los 9 días de navegación, a partir de la cifra en millas, no difiere mucho del dato que se aporta al final, que "la navegación es de diez días y diez noches", pues sumarían 560.000 pasos en 10 días en vez de los 496.000 indicados para 9 días, donde habría que incluir la distancia hasta el río Banbotum o río Aoueri en Mar Pequeña, que al menos requeriría un día o uno y medio desde el río Drâa. Por otra parte, esos 10 días de navegación se relacionan con el promontorio Hespéru Keras o Cabo Juby, que para alcanzarlo desde el Drâa exigiría 1 o 2 días más de navegación, aunque no queda claro que se haya visitado.

Por otra parte, si asumimos que la distancia de 616.000 pasos debe proceder de Juba II por la relación con 56 millas diarias de navegación, que el río Salsum se

135 Sol. 24, 12.

136 Gossellin 1797-1798, 112.

137 LIPINSKI 2004, 464.

138 PÉdech 1955, 324; LóPez Pardo 2009, 45. 
corresponde bien con los selatitos de Juba II y que entre los pueblos del interior se mencionan a los gétulos daras, los cuales no son citados por Polibio, la impresión que se obtiene es que realmente el párrafo también corresponde a Juba II, y del rey mauretano procede tanto la información sobre los pueblos costeros, etíopes perorsos y etíopes daratitas, como la de los pueblos del interior, farusios y gétulos daras.

Si frente a lo que proponemos, el Anatis se situase en el río Oum er-Rbia, por asociarse con el Asana de Ptolomeo, podría pensarse que Polibio sólo alcanzó la zona de Kérne o islote de Mogador. No obstante, si como hemos sugerido, los 10 días de navegación no son la distancia entre el Theôn Óchema y el Hespéru Keras, al contradecirse con Plinio, ${ }^{139}$ sino un trayecto de navegación del golfo entre Cabo Aguer y Cabo Juby, muy similar a los 11 días recorriendo 56 millas diarias que salen por golfo de 616.000 pasos, y a los 9 días del Atlas al río Anatis, sí es posible que Polibio recorriera una parte de este golfo.

Finalmente indicar, respecto a las velocidades de los trayectos, que no es lo mismo un viaje exploratorio que una ruta regular. Un ejemplo lo vemos en las distancias desde el Océano, es decir Septem o Gadir con Cartago, o entre Gadir y Roma. La primera ruta era recorrida en sólo 7 días a finales del siglo IV a.C., según el periplo de Pseudo-Scílax, ${ }^{140}$ pero si la pasamos a miles de pasos con la velocidad que recorrían explorando los barcos la costa africana apenas serían $56 \times 7$ días y noches $=392.000$ pasos. Como sabemos por Plinio ${ }^{141}$ que Polibio estimó esta distancia en 1.100 .000 pasos, implica que la velocidad alcanzada era 157 millas o miles de pasos, es decir, casi triplicaban la velocidad de exploración. Podría pensarse que la distancia está mal calculada, pero también Plinio ${ }^{142}$ señala que Gadir y Ostia estaban a 7 días (y noches) de navegación.

\section{Límite del viaje y trayecto de regreso}

Se ha planteado que la referencia casi al final del río Banbotum con cocodrilos e hipopótamos sería una interpolación de un comentarista griego por la presencia de cocodrilos en el río Darat, ${ }^{143}$ hipótesis que se ha considerado ingeniosa pero frágil. ${ }^{144} \mathrm{El}$ nombre, Bambotum, con $m$ en vez de $n$, más frecuente en los manuscritos, ${ }^{145}$ ha sido interpretado como una corrupción de Bamothum, del hebreo behemoth, "hipopótamo". ${ }^{146}$ Los cocodrilos los atribuye Mauny ${ }^{147}$ a la especie Varanus niloticus, grandes saurios de $1 \mathrm{~m}$ de longitud, e incluso los cocodrilos hoy se encuentran en la misma latitud, en el Nilo y en el Tassili n-Ajjer. Por el contrario, no existen eviden-

\footnotetext{
139 Plin. N.H., VI, 197.

140 Ps-Scilax Peripl., 112.

141 Plin. N.H., V, 40.

142 Plin. N.H., XIX, 4.

143 Aly 1927, 338.

144 Desanges 1980, 118.

145 Desanges 1978, 417.

146 Job, 40, 15; Bochart 1646.

147 Mauny 1970, 103.
} 
cias de hipopótamos e incluso son rarísimos entre los grabados rupestres, solamente los encontramos en el Oued Djerat (Tassili n-Ajjer) y en Gonoa (Tibesti).

Si el río Banbotum fue el final del trayecto, pues los datos geográficos a partir de entonces son más vagos y no hay coincidencia con la distancia entre el Theôn Óchema y el Hespéru Keras respecto a Plinio, ${ }^{148}$ y situamos el límite meridional en el río Drâa, la expedición de Polibio pudo regresar costeando sin haber visualizado las Islas Canarias.

$\mathrm{Si}$, como proponemos, el río Banbotum era el río Aoueri en Mar Pequeña, pudiera ser posible que no se visualizasen las islas en el trayecto de regreso si se remontó bordeando muy próximo a la costa. Sin embargo, si se sitúa el río Banbotum en el río Seguia el-Hamra, como sugieren varios autores, ${ }^{149}$ resulta muy dudoso que no las atravesasen al remontar por medio de las Canarias Orientales, entre Gran Canaria y Fuerteventura o entre Gran Canaria y Tenerife, donde la visión del Teide sería un elemento dominante. Pero al no mencionarse ningún dato sobre las islas procedente de Polibio, se puede pensar que el último río visitado fue el Banbotum o actual río Aoueri en Santa Cruz de Mar Pequeña.

La referencia final de que "a partir de él hay una sucesión de montañas hasta la que llamaremos Theôn Óchema" no resulta muy fiable al no ser observada directamente, pues se trata en una costa llana y desértica, salvo los sectores acantilados, pero en ningún caso montañosa como puede serlo en la región del Atlas en el entorno de Mogador y en Cabo Aguer, o en la región del Anti-Atlas del entorno de Ifni. Por otra parte, Desanges ${ }^{150}$ considera aberrante y fruto de una interpolación que el volcán Theôn Óchema se mencione antes del Hespéru Keras o Cuerno del Oeste.

Debe tenerse en cuenta, al valorar esta "sucesión de montañas hasta (...) Theôn Óchema", que puede deberse a que Polibio sugería en uno de sus libros no conservados "que la región situada bajo el Ecuador es más elevada", probablemente por pensar que "las lluvias que colman el Nilo provienen de las montañas de Etiopía". 151

\section{Conclusiones}

El Periplo de Polibio, realizado por la fachada atlántica norteafricana al final de la Tercera Guerra Púnica, presumiblemente durante el verano de 146 a.C., muestra el inicio de la proyección de Roma hacia el Mar Exterior u Océano Atlántico, que el segundo tratado romano-cartaginés del 348 a.C. había impedido en las costas norteafricanas hasta el final de la Segunda Guerra Púnica, el 201 a.C.

El texto parece utilizar dos fuentes, pues ambas terminan en el entorno del río Drâa, una más antigua del propio Polibio, ${ }^{152}$ donde también aprovecha fuentes anteriores, pues utiliza una toponimia más antigua que se retrotrae hasta el periplo de Hannón,

148 Plin. N.H., VI, 197; Gossellin 1797-98, 119; Pédech 1955, 330-331; Desanges 1978, 128.

149 Gsell 1928, 298; Pédech 1955, 329; Desanges 1978, 141; ID. 1980, 117-118; López Pardo $2000,84$.

150 Desanges 1980, 119; ID. 2000, 145.

151 Str. II, 3, 3.

152 Plin. N.H., V, 10. 
caso de Kérne, Banbotum o Theôn Óchema. Además, hay datos de poblaciones del interior que no proceden de Hannón, los cuales difícilmente pudieron obtenerse en un periplo de exploración costero y parecen ser más recientes por la mención de los getulos.

La segunda fuente ${ }^{153}$ no puede ser Polibio porque hay detalles, como la mención de los getulos, nuevamente, sobre los cuales indica Desanges ${ }^{154}$ nunca son citados en sus textos y aparecen por primera vez en Salustio. ${ }^{155}$ Tradicionalmente se ha atribuido a Agripa, pero lo más lógico es que sea Juba II, quien envió una expedición naval a inicios de su reinado en la Mauretania, a partir del 25 a.C., ${ }^{156}$ cuya parte final, relativa a la exploración de las Islas Canarias, está bien identificada por conservarse la mención de su nombre en Plinio, ${ }^{157}$ pero era incomprensible que faltase cualquier dato de su recorrido costero norteafricano, al menos para la región centro-meridional del actual Marruecos, de la cual no poseía un control político directo.

El objetivo del viaje de Polibio debió ser informar por parte romana, y en concreto por Escipión el Africano, que Cartago había sido destruida y que estas regiones pasaban a estar dentro de la órbita política de Roma, a lo que se sumaría un interés exploratorio sobre la ruta marítima de procedencia del oro en polvo subsahariano, que alcanzaba por la ruta terrestre hasta la región de los Emporios del golfo de las Sirtes.

La parte que se ha conservado del periplo de Polibio aporta una información toponímica muy escasa, una ciudad, Lixus, la isla de Kérne, y tres ríos, Anatis, SalsumPalsum y Banbotum. A partir de las menciones de los getulos daras o de los etíopes daratitas, podemos presumir que conoce también el río Darat, pero la mención de getulos sugiere como fuente a Juba II, como ya hemos señalado. La parte final es menos precisa, con menciones de montes costeros incluyendo el Theôn Óchema, dentro de la idea de Polibio de que en estas regiones ecuatoriales montañosas nacía el río Nilo, o la ubicación del volcán Theôn Óchema antes del Hespéru Keras o Cuerno de Occidente, y no después de este cabo como en Hannón, ${ }^{158}$ que sí parece haberlo divisado.

De las dos distancias que recoge Plinio de Polibio, una coincide con Solino, ${ }^{159}$ la distancia entre la montaña Atlante y el río Anatis de 496.000 pasos o 9 noches de navegación. Sobre la segunda cifra, 205 millas, Plinio indica que se trata de la distancia entre el río Anatis y la ciudad de Lixus, pero Solino ${ }^{160}$ indica que "el Atlas -no el Anatis - dista de Lix 205.000 pasos", unos 4 días de navegación. Por Plinio ${ }^{161}$ sabemos que había un día de navegación entre el río Salé, actual Bou Regreg, y el río Sebou, y otro día desde el Sebou hasta Lixus. Nuestra hipótesis es que el río Anatis se

153 Plin. N.H., V, 9.

154 Desanges 1978, 125.

155 Sal. Iug., LXXX, 1.

156 Dio. Cas. LIII, 26, 2; Str. VI, 4, 2. Para la obra de Dión Casio se han manejado las ediciones de la Biblioteca Clásica Gredos ( $\mathrm{n}^{\circ}$ 395, libros L-LX, de 2011, con traducción de J. M. Cortés Copete) y The Loeb Classical Library (n 83, vol. VI, libros LI-LV, de 1960, a cargo E. Cary).

157 Plin. N.H., VI, 202-205.

158 Hanno Peripl., 14, 16.

159 Sol. 24, 12.

160 Sol. 24, 11.

161 Plin. N.H., V, 5. 
encontraría a 9 días de navegación hacia el Sur desde el inicio de la región del Atlas, al sur del río Oum er-Rbia.

Esto implicaría que la información de los ríos que nos proporciona Polibio es toda del sur de Marruecos, la región más desconocida para los romanos, con los ríos Salsum-Palsum, Anatis y Banbotum. Si el Salsum lo asociamos con el Sous, y sus habitantes son los selatitos que citaba el periplo de Juba II, de quien puede proceder el nombre del río, y el Banbotum sería el río Aoueri, en Santa Cruz de Mar Pequeña, utilizando el nombre que le dio Hannón, creemos que el Anatis debe ser una denominación antigua del río Drâa que, por su gran extensión hasta el interior de la actual Argelia, se identificaba con una posible desembocadura atlántica del río Nilo y explicaría que se mencionen en su cauce bajo los etíopes daratitas y en su cauce medio los getulos daras, datos ambos de Juba II.

El periplo de Juba II aporta una información toponímica más reciente y precisa, aunque tampoco es demasiado abundante. En su parte inicial atraviesa una región conocida donde Juba II tenía control político efectivo y no era lógicamente el objetivo de la expedición exploratoria. Sólo menciona las tres ciudades principales de la costa, seguramente todas fundaciones fenicias, Lixus, Sala y Rutubis, y los tres principales ríos, Sububa [Sebou], Salat [Salé, Bou Regreg], más el Oum er-Rbia si situamos el puerto de Rutubis en Azemmour, en la desembocadura de ese río.

Pasado el Cabo Cantín o Promontorio del Sol, se entraba en el territorio de los getulos autololes, mencionándose una única localidad, el puerto de Rhysaddir, Rs addir, "cabo prominente" o "Cabo de las - montañas-imponentes" [Mogador y Cabo [Baal] Hadid algo más al Sur], y tres cursos fluviales, el río Cuoseno [Ksob, junto a Mogador], el río Masathat [Massa] y el río Darat [Drâa, Dr, "río imponente"], además de dos pueblos costeros próximos a ríos, los selatitos [del río Salsum, Sous] y los masatos [del río Massa]. Algunos datos que se atribuyen a Polibio como la mención del río Salsum deben ser también de Juba, porque en ese párrafo también se mencionan a los getulos daras, y explicaría que Polibio use Anatis para el Drâa y Juba II el de Darat.

La referencia al golfo Surrentium, desde Monte Braca o Atlas, en el entorno de Cabo de Aguer o Ghir, hasta el río Banbotum con 616.000 pasos, una navegación de 11 días y noches, atribuida tradicionalmente a Polibio, creemos que también corresponde a Juba II por su equivalencia en el uso de una navegación de exploración cubriendo jornadas de 56 millas diarias.

En conclusión, nos encontramos con un trayecto de 17 días y 952.000 pasos entre Gadir o Septem Fratres y el río Darat [Drâa] en Juba II o Banbotum [río Aoueri en Mar Pequeña] en Polibio, al que si le sumamos para el trayecto entre Rutubis [Azemmour] y el cabo Surrentium [Aguer] otros 224.000 pasos, 56 x 4 días y noches, totalizan 21 días y 1.176.000 pasos, que puede compararse con los 1.296 .000 pasos o 23 días de navegación de exploración como extensión máxima de África según Agripa. ${ }^{162}$

162 Plin. N.H., VI, 196. 


\section{Anexo}

\begin{tabular}{l}
\hline Plinio, N.H. V, 9-10 163 \\
\hline (9) Scipione Aemiliano res in Africa \\
gerente Polybius annalium conditor, ab \\
eo acepta classe scrutandi illius orbis \\
gratia circumvectus, prodidit a monte eo \\
ad occasum versus saltus plenos feris, \\
quas generat Africa; ad flumen Anatim \\
CCCCLXXXXVI, ab eo Lixum CCV. \\
Agrippa Lixum a Gaditano freto CXII \\
abesse; inde sinum qui vocetur Sagigi, \\
oppidum in promunturio Mulelacha, \\
flumina Sububam et Salat, portum Rutubis \\
a Lixo CCXXIIII, inde promunturium Solis, \\
portum Rhysaddir, Gaetulos Autoteles, \\
flumen Quosenum, gente[s] Selatitos et \\
Masat[h]os, flumen Masath[at], flumen \\
Darat, in quo crocodilos gigni.
\end{tabular}

(10) dein sinum DCXVI includi montis Bracae promunturio excurrente in occasum, quod appelletur Surrentium. postea flumen Salsum, ultra quod Aethiopas Perorsos, quorum a tergo P[h]arusios. his iungi [in] mediterraneo Gaetulos Daras, at in ora Aethiopas Darat[h]itas, flumen Bambotum, crocodilis et hippopotamis refertum. ab eo montes perpetuos usque ad eum, quem Theon Ochema dicemus. inde ad promunturium Hesperu navigatione [m] dierum ac noctium decem. in medio eo spatio Atlantem locavit, ceteris omnibus in extremis Mauretaniae proditum

\section{Traducción de Alicia $\mathrm{M}^{\mathrm{a}}$. Canto}

(9) Estando al mando de África Escipión Emiliano, Polibio, el autor de los Anales, habiendo recibido de aquél una flota para navegar alrededor de aquel continente, relata que desde el dicho monte Atlas hacia el oeste hay bosques llenos de las fieras que produce África, y que desde él hay 496 millas hasta el río Anatis, y a Lixo 205 (Agripa dice que Lixo dista del estrecho gaditano sólo 112). A partir de allí se suceden el golfo llamado Sagigi, la ciudad de Mulelacha en el cabo, los ríos Sububa y Salat y el puerto de Rutubi (que dista 224 millas de Lixo). A partir de éste, el Cabo del Sol, el puerto de Rusadir, los Gétulos Autololes, el río Quoseno, las tribus de Selatitos y Masathos, el río Masathat y el río Darat, en el que se crían cocodrilos.

(10) A partir de él viene un golfo de 616 millas que abraza el cabo que es llamado Surrentio, saliente hacia el ocaso del monte Braca. A continuación está el río Salso, más allá del cual están los Etíopes Perorsos, a cuya espalda se hallan los Farusios. Contiguos a éstos, en el interior, se hallan los Gétulos Daras pero, de nuevo en la costa, los Etíopes Daratitas y el río Banboto, abundante en cocodrilos e hipopótamos. Desde este río hay montañas continuas, hasta la que llamaremos Theon Ochema. De allí hasta el Cabo del Oeste hay una navegación de diez días y diez noches. En medio de este espacio es donde situó el Atlas, referido por todos los demás en los extremos de Mauretania.

163 Mayhoff 1906, 363-364; Desanges 1980, 49-50. 


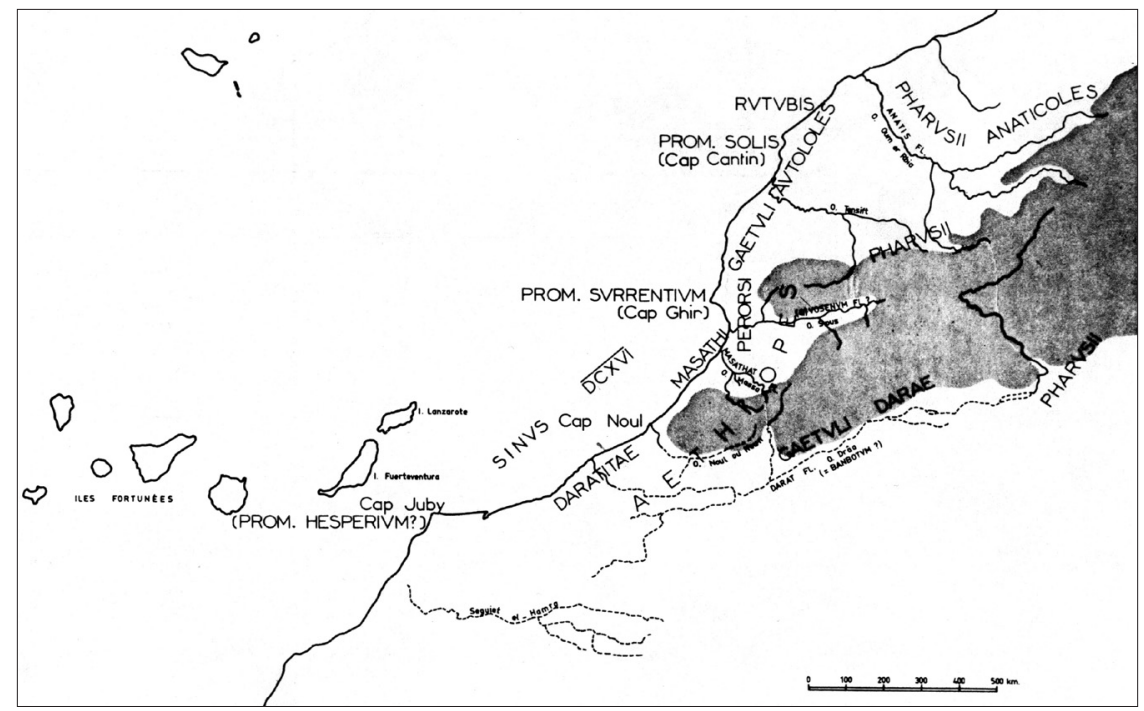

Fig. 1. Periplo de Polibio según Desanges (1978).

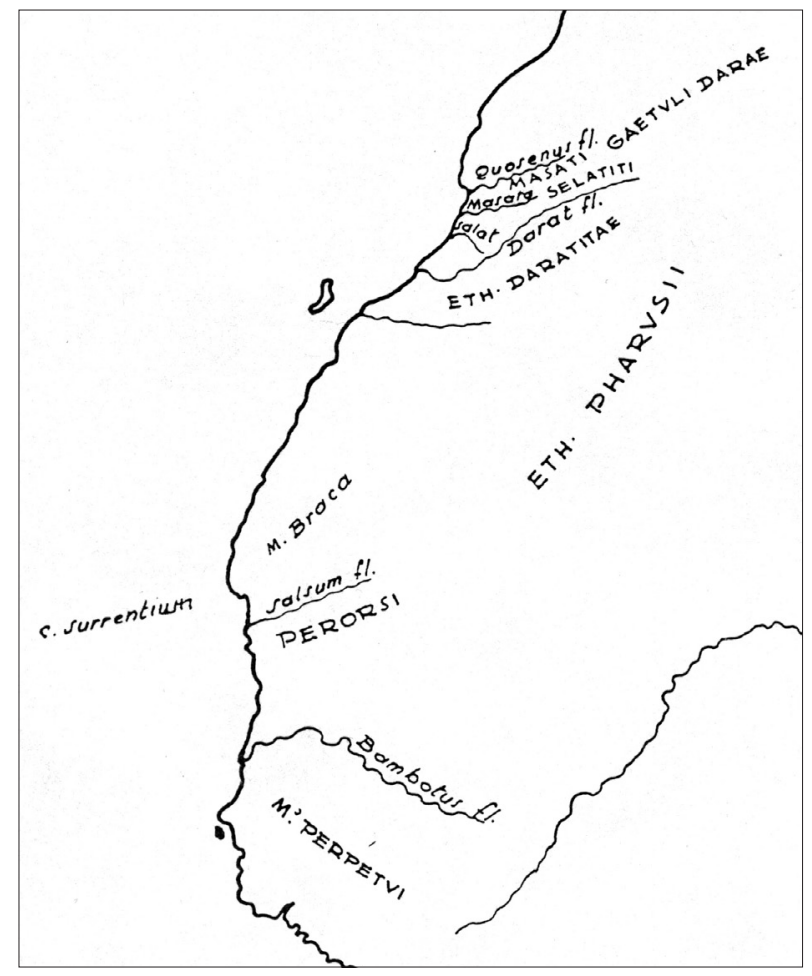

Fig. 2. Periplo de Polibio según Thouvenot (1948). 


\section{Bibliografía}

Antichan, P. H. (1888): Grands voyages de découvertes des anciens, Paris.

Aly, W. (1927): "Die Entdeckung des Westens", Hermes 62, 299-341 y 485-489.

Avelot, R. (1908): “L'Afrique occidentale au temps des Antonins”, Bulletin de Géographie historique et descriptive du Comité des Travaux Historiques et Scientifiques 23/1-2, 37-80.

Balbín, R. de - Bueno, P. - GonzÁlez Antón, R. - Arco, Ma C. Del (1995): “The Zinete Stone", Sahara 7, 39-50.

Berlioux, E. F. (1884): La terre habitable vers l'Équateur par Polybe. Notice sur cet ouvrage et Sur les itinéraires des Anciens dans l'Afrique occidentale, Paris.

Berthelot, A. (1927): L'Afrique Saharienne et Soudanaise (=Ce qu'en ont connu les Anciens, Bibliothèque Documentaire, Les Arts et le Livre), Paris.

Besnier, M. (1906): "La géographie économique du Maroc dans l'Antiquité", Archives Marocaines $7,271-293$.

Blázquez y Delgado-Aguilera, A. (1921): "Las costas de Marruecos en la Antigüedad", Boletín de la Real Academia de la Historia 79, 400-418 y 481-509.

Blázquez Martínez, J. Ma (1977): "Las Islas Canarias en la Antigüedad", Anuario de Estudios Atlánticos 23, 35-51.

Bochart, S. (1646): Geographiae sacrae pars prior, Phaleg, seu de dispersione gentium et terrarum divisione facta in aedificatione turris Babel pars altera, Chanaan, seu de coloniis et sermone Phoenicum, Caen.

Bunbury, E. H. (1879): A History of Ancient Geography among the Greeks and Romans from the Earliest Ages till the Fall of the Roman Empire, I, London.

CAmps, G. (1960): Aux origines de la Berbèrie. Massinisa ou les débuts de l'histoire, Libyca, Archéologie-Épigraphie 8 (1), Alger.

CARCopino, J.

(1943a): Le Maroc Antique, Paris.

(1943b): "Étude critique du Périple d'Hannon", Comptes Rendus de la Académie des Inscriptions \& Belles-Lettres 1943, 137-139, 149-151 y 152-154.

(1948): “Du Périple d'Hannon aux portulans grecs du XVI" siècle", Mélanges Charles Picard, Revue Archeologique 29-30, 132-141.

CARY, M. - Warmington, E. H.

(1929): The Ancient Explorers, London.

(1929/1932): Les Explorateurs de l'Antiquité, Paris.

CAsariego Fernández-Noriega, J. E.

(1947): El Periplo de Hannon de Cartago, Madrid.

(1949): Los grandes periplos de la Antigüedad. Breve historia de las navegaciones clásicas, Madrid.

(1950): "Las grandes exploraciones marítimas del África en la Antigüedad", Archivos del Instituto de Estudios Africanos 14, 7-38.

Cichorius, C. (1908): "Panaitios und die attische Stoïker-inschrift", Rheinisches Museum für Philologie N.F. 63/2, 197-223.

Culican, W. (1991): "Phoenicia and Phoenician Colonization", The Cambridge Ancient History. III (2), [en] J. Boardman - I. E. S. Edwards - N. G. L. Hammond - E. Sollberger - C. 
B. F. Walker (eds.), The Assyrian and Babylonian Empires and other States of the Near East. From the Eighth to the Sixth Centuries B.C., Cambridge, 2a ed., 461-546.

Cunliffe, B. (2001): Facing the Ocean. The Atlantic and its Peoples 8000 BC-AD 1500, Oxford.

Decret, F. (1977): Carthage ou l'empire de la mer, Paris.

Desanges, J.

(1978): Recherches sur l'activité des méditerranéens aux confins de l'Afrique (VI siècle avant J.C.-IV siècle après J.C.) (=Collection de l'École Française de Rome 38), Roma.

(1980): Pline l'Ancien. Histoire Naturelle. Livre V, 1-46. $1^{\text {ere }}$ partie (L'Afrique du Nord), Paris.

(2000): “D'une Corne à l'autre: retour sur le Périple d'Hannon", [en] Ma . E. Aubet - M. Barthélemy (eds.), IV Congreso Internacional de Estudios Fenicios y Púnicos (Cádiz 1995), Cádiz, I, 141-146.

(2001): "Les îles Fortunées et leur environnement africain d'après Pomponius Méla et Pline l'Ancien", [en] C. Hamdoune (ed.), Vbiqve amici. Mélanges offerts à Jean-Marie Lassère, Montpellier, 19-34.

DetLEFSEN, D.

(1904): Die geographischen Bücher (II, 242-VI Schlufs) der Naturalis Historia des C. Plinius Secundus, [en] W. Sieglin (ed.), Quellen und Forschungen zur alten Geschichte und Geographie 9, Berlin.

(1906): Ursprung, Einrichtung und Bedeutung der Erdkarte Agrippas, [en] W. Sieglin (ed.), Quellen und Forschungen zur alten Geschichte und Geographie 13, Berlin.

Díaz del Río Recacho, J. (2005): “El Periplo de Hannón”, [en] V. Peña - C. González Wagner - A. Mederos (eds.), La navegación fenicia: tecnología naval y derroteros, Madrid, $155-178$.

Dilke, O. A. W. (1985): Greek and Roman Maps, Ithaca, New York.

Eichel, M. H. - TodD, J. M. (1976): “A note on Polybius' Voyage to Africa in 146 B.C.", Classical Philology 71/3, 237-243.

EUZENNAT, M.

(1990-1992): "Retour à Cernè”, Bulletin du Comité des Travaux Historiques, N.S., Afrique du Nord 23B, 222-223.

(1994): “Le Périple d'Hannon”, Comptes Rendus de l'Académie des Inscriptions et BellesLettres 1994, 559-580.

Ferguson, J. (1969): “Classical Contacts with West Africa”, [en] L. Thompson - J. Ferguson (eds.), Africa in Classical Antiquity, Ibadan, 1-25.

García Moreno, L. A.

(1989): "Precedentes grecorromanos de la navegación atlántica de Bartolomeu Dias: en torno al Periplo de Hanón”, Bartolomeu Dias e a sua época, Porto, vol. II, 237-257.

(1993): "Egipto y la circunnavegación de África en la antigüedad", Boletín de la Asociación Española de Orientalistas 29, 61-76.

García Moreno, L. A. - Gómez Espelosín, F. J.

(1996a): "Periplo del Pseudo Escílax", Relatos de viajes en la literatura griega antigua, Madrid, 37-98.

(1996b): "Periplo de Hanón", Relatos de viajes en la literatura griega antigua, Madrid, 99-121. 
Gattefosse, J. (1932): “L'Atlantide et le Tritonis occidental. Le rôle des peuples du Sahara occidental dans le développement de la Civilisation", Bulletin de la Société de Préhistoire du Maroc 6/2, 51-152.

Gautier, E. F. (1942): Le passé de l'Afrique du Nord. Les siècles obscurs, Paris.

Gómez Espelosín, F. J.

(1994): "Tierras fabulosas del imaginario griego", [en] F. J. Gómez Espelosín - A. Pérez Largacha - M. Vallejo, Tierras Fabulosas de la Antigüedad, Alcalá de Henares, 101-303. (2000): El descubrimiento del mundo. Geografía y viajeros en la antigua Grecia, Madrid.

González Antón, R. - Balbín, R. De - Bueno, P. - Arco, Ma C. Del (1995): La piedra zanata, La Laguna.

Gossellin, P. F. J. (1797-1798): Recherches sur la géographie systématique et positive des anciens; pour servir de base à l'histoire de la géographie ancienne, I, Paris.

GonzÁlez Ponce, F. J.

(2003-2007): "Xénophon de Lampsaque et le Périple de Hannon de Heidelberg”, Orbis Terrarum 9, 95-118.

(2009): Periplógrafos griegos I. Épocas Arcaica y Clásica I: Periplo de Hanón y autores de los siglos VI y V a.C. (=Monografías de Filología Griega 19), Zaragoza.

(2010): "Veracidad documental y deuda literaria en el Periplo de Hanón, 1-8", [en] E. Ferrer (ed.), VI Coloquio Internacional del Centro de Estudios Fenicios y Púnicos: Los púnicos de Iberia. Proyectos, revisiones, sintesis (Sevilla 2009), (= Mainake 32/2), Sevilla, 761-780.

Gozalbes Cravioto, E.

(1993a): “Algunas observaciones acerca del Periplo de Hannon”, Hispania Antiqua 17, 7-19.

(1993b): “Comercio y exploración del Sahara en la Antigüedad Clásica”, Estudios Africanos 7 (12-13), 9-33.

(2000): "Más allá de Cerné”, Eres (Arqueología) 9/1, 9-42.

(2002): "Los pueblos del África Atlántica en la Antigüedad”, Eres (Arqueología) 10, 6196.

(2011): “África en el imaginario: las exploraciones geográficas del rey Juba II de Mauretania”, Studia Historica, Historia Antigua 29, 153-181.

GsEll, ST.

(1913a): Histoire ancienne de l'Afrique du Nord. Tome I. Les Conditions du développement historique. Les Temps primitifs. La Colonisation phénicienne et l'Empire de Carthage, Paris.

(1913b): Histoire ancienne de l'Afrique du Nord. Tome II. L'état carthaginois, Paris.

(1918): Histoire ancienne de l'Afrique du Nord. Tome III. Histoire Militaire de Carthage, Paris.

(1927): “Juba II, Savant et Ecrivain”, Revue Africaine 68/3, 169-197.

(1928a): "Connaissances géographiques des grecs sur les côtes africaines de l'océan", Mémorial Henri Basset. Nouvelles études nord-africaines et orientales (=Institut des HautesÉtudes Marocaines 17), Paris, 293-312.

(1928b): Histoire ancienne de l'Afrique du Nord. Tome VIII. Jules César et l'Afrique. Fin des royaumes indigènes, Paris.

GuARner, V. (1932): "Lo que fue conocido en otros siglos sobre el Sahara Occidental y el Sur Marroquí actuales", África 93, 165-168. 
Hardouin, J. (1685): Caii Plinii Secundi Naturalis Historiae libri XXXVII, Paris.

Hennig, R. (1936): Terrae incognitae. Eine Zusammenstellung und kritische Bewertung der wichtigsten vorcolumbischen Entdeckungsreisen an Hand der darüber vorliegenden Originalberichte. I. Altertum bis Ptolemäus, Leiden.

Huss, W.

(1990): Die Karthager, München.

(1990-1993): Los Cartagineses, Madrid.

Jodin, A.

(1987): Volvbilis Regia Ivbae. Contribution à l'étude des civilisations du Maroc antique préclaudien (=Publications du Centre Pierre Paris 14), Paris.

(1988): "Les Phéniciens à Mogador", Les Phéniciens a la conquête de la Méditerranée, Les Dossiers de Histoire et l'Archéologie 132, 88-91.

Jorge Godoy, S. (1996): Las navegaciones por la costa atlántica africana y las Islas Canarias en la antigüedad (=Estudios Prehispánicos 4), Tenerife.

Keyser, P. T. (1993): "From Myth to Map. The Blessed Isles in the First Century B.C.", The Ancient World 24/2, 149-168.

KLotz, A. (1906): Quaestiones Plinianae geographicae, [en] W. Sieglin (ed.), Quellen und Forschungen zur alten Geschichte und Geographie 11, Berlin.

Laffranque, M. (1963): "Poseidonios, Eudoxos de Cyzique et la circumnavigation de l'Afrique", Revue Philosophique de la France et de l'étranger 153/2, 199-222.

Lelewel, J. (1831): Die Entdeckungen der Carthager und Griechen auf dem atlantischen Ocean, Berlin.

Lenormant, F. (1869): Manuel d'Histoire Ancienne de l'Orient jusqu'aux Guerres médiques. III. Phéniciens-Arabes-Indiens, Paris.

LIPINSKI, E.

(1992): Dictionnaire de la Civilisation Phénicienne et Punique, Turnhout.

(1995): "The Phoenicians", [en] J.M. Sasson (ed.), Civilizations of the Ancient Near East. II, New York, 1321-1333.

(2004): Itineraria Phoenicia (=Studia Phoenicia 18; Orientalia Lovaniensia Analecta 127), Leuven-Dudley, Ma.

LóPez PARdo, F.

(1991): "El Periplo de Hannon y la expansión cartaginesa en el África Occidental", [en] La Caída de Tiro y el auge de Cartago. V Jornadas de Arqueología Fenicio-Púnica (Ibiza 1990), (=Trabajos del Museo Arqueológico de Ibiza 25), Ibiza, 59-71.

(2000): El empeño de Heracles. La exploración del Atlántico en la Antigüedad, Madrid.

(2004): "Puntos de mercado y formas de comercio en las costas atlánticas de la Lybie en época fenicio-púnica", [en] F. Chaves - R. González Antón (eds.), Fortunatae Insulae (Tenerife 2004), Catálogo de Exposición, Tenerife, 85-100.

(2009): "Marinos y colonos fenicios codificando la costa atlántica africana", [en] J. M. Candau - F. J. González Ponce - A. L. Chávez (eds.), Libyae Lustrare Extrema. Realidad y literatura en la visión grecorromana de África. Estudios en honor del Profesor Jehan Desanges (=Monográficos de Philologia Hispalensis), Sevilla, 25-51.

López Pardo, F. - Mederos, A. (2008): La factoría fenicia de la isla de Mogador y los pueblos del Atlas (=Canarias Arqueológica Monografías 3), Sevilla-Tenerife. 
MARCY, G.

(1935): "Notes linguistiques autour du périple d'Hannon", Hespéris 21/1-2, 21-72.

(1943-1945): “Le 'Périple d'Hannon' dans 'Le Maroc antique' de M. Jérôme Carcopino”, Journal Asiatique 234, 1-57.

Martín de GuZmán, C. (1997): "De arqueología canaria: planteamientos teóricos e historiográficos", [en] A. Millares - P. Atoche - M. Lobo (eds.), Homenaje a Celso Martín de Guzmán (1946-1994), Madrid-Las Palmas, 29-64.

MARTiniêRe, H. M. DE la (1912): “Esquisse de l'histoire du Maroc avant l'arrivée des Arabes”, Bulletin Archéologique du Comité des Travaux Historiques et Scientifiques 1912, 142-184.

MAUnY, R.

(1949): “Autour d'un texte bien controversé: le 'périple' de Polybe (146 av. J.C.)”, Hespéris 36/1, 47-67.

(1950): "L'Ouest africain chez Ptolémée (vers +141 J.-C)", II ${ }^{a}$ Confêrencia Internacional dos Africanistas Ocidentais (Bissau 1947), Lisboa, vol. I, 241-293.

(1951a): "Notes sur le périple d'Hannon", I ère Conférence Internationale des Africanistes de l'Ouest (Dakar 1945), Paris, vol. II, 507-530.

(1951b): "Le Sahara chez Ptolémée", Bulletin de Liaison Saharienne 2, 18-23.

(1955): "La navigation sur les côtes du Sahara pendant l'Antiquité", Revue des Études Anciennes 57, 92-101.

(1970a): Les siècles obscurs de l'Afrique noire. Histoire et archéologie, Paris.

(1970b): "Le Périple d'Hannon. Un faux célèbre concernant les navigations antiques", Archéologie 37, 76-80.

(1974-1975): “L'ile de Herné (Golfe du Rio de Oro) et l'identification de l'ile de Cerné des Anciens", Almogaren 5-6, 328-331.

(1978): "Trans-Saharan Contacts and the Iron Age in West Africa", [en] J. D. Fage (ed.), The Cambridge History of Africa. 2. From c. 500 BC to AD 1050, Cambridge, 272-341.

MEDAS, S. (2006): “...Essendo finiti $i$ viveri, non navigammo oltre”. Introduzione allo sudio del Periplo di Annone (=Temi di Archeologia Punica 2), Lugano.

Mederos, A. - Escribano, G. (2004): "Los periplos de Eudoxo de Cízico en la Mauretania atlántica", Gerión 22/1, 215-233.

Millán León, J. (1998): Gades y las navegaciones oceánicas en la Antigüedad (1000 a.C.500 d.C.), Écija-Sevilla.

MÜLLER, K.

(1855): Geographi Graeci minores. E codicibus recognovit, prolegomenis, annotatione, indicibus instruxit, tabulis aeri incisis illustravit Carolus Mullerus, I, A., Paris.

(1883-1901): Claudii Ptolemaei Geographia, I-II, Paris.

Mveng, E. (1970-1972): Les sources grecques de l'histoire négro-africaine depuis Homère jusqu'à Strabon, Thèse de la Faculté de Lettres et Sciences Humaines de Paris, Service de reproduction des thèses, Université de Lille III, Lille.

Oтtоne, G. (2000): "Problemi relative alla conoscenza della topografia nord-africana nel Peri Libýes di Mnasea", [en] M. Khanoussi - P. Ruggeri - C. Vismara (eds.), L'Africa Romana XIII. Geografi, viaggiatori, militari nel Maghreb: alle origini dell'archeologia nel Nord Africa (Djerba, 1998), Roma, 177-188.

PÉDECH, P.

(1955): "Un texte discuté de Pline: le voyage de Polybe en Afrique (H.N., V, 9-10)", Revue des Études Latines 33, 318-332. 
(1964): La méthode historique de Polybe, Paris.

Peretti, A. (1979): Il periplo di Scilace. Studio sul primo portolano del Mediterraneo (=Biblioteca di Studi Antichi 23), Pisa.

Picard, G. CH. - Picard, C. (1958): La vie quotidienne à Carthage au temps d'Hannibal. III siècle avant Jésus-Christ, Paris.

Ponsich, M. (1982): “Territoires utiles du Maroc punique”, [en] H. G. Niemeyer (ed.), Phönizier im Westen (Koln 1979), Mainz am Rhein, 429-444.

Quatremère, E. M. (1845-1857): “Die Phoenizier (les Phéniciens) von Dr. Movers, T. I, 1841; t. II, $1^{\text {ère }}$ partie, $1849,2^{\text {e }}$ partie, 1850; t. III, $1^{\text {èr }}$ partie, 1856", Journal des Savants 1857 , 249-267.

Ramin, J. (1976): Le Périple d'Hannon (=British Archaeological Report, Supplementary Series 3), Oxford.

REBUFFAT, R.

(1985-86): "Recherches sur le bassin du Sebou, II. Le Périple d'Hannon", Bulletin d'Archéologie Marocaine 16, 257-284.

(1988): "Voyage du Carthaginois Hannon, du Lixos à Cerné", Bulletin Archéologique du Comité des Travaux Historiques, N.S., Afrique du Nord 18B, 198-201.

Roget, R. (1938): Index de Topographie Antique du Maroc, Paris.

Roller, D. W. (2006): “The West African Voyage of Hanno the Carthaginian”, The Ancient World 37/2, 115-125.

Rousseaux, M. (1949): “Hannon au Maroc”, Revue Africaine 93/420-421, 161-232.

SAgazan, L. M. DE (1956): "L'exploration par Juba II des îles Purpuraires et Fortunées", Revue Maritime 125, 1112-1121.

SAntana, A. - Arcos, T.

(2002): "El conocimiento geográfico del Océano en la Antigüedad", Eres (ArqueologíaBioantropología) 10, 5-59.

(2006): "Las dos islas Hespérides atlánticas (Lanzarote y Fuerteventura, Islas Canarias, España) durante la Antigüedad: del mito a la realidad", Gerión 24, 85-110.

(2009): "La descripción de África en Plinio (Nat. V y VI)", [en] J. M. Candau - F. J. González Ponce - A. L. Chávez (eds.), Libyae Lustrare Extrema. Realidad y literatura en la visión grecorromana de África. Estudios en honor del Profesor Jehan Desanges (=Monográficos de Philologia Hispalensis), Sevilla, 347-360.

Santana, A. - Arcos, T. - Atoche, P. - Martín Culebras, J. (2002): El conocimiento geográfico de la costa noroccidental de África en Plinio: la posición de las Canarias (=Spudasmata 88), Hildesheim.

SchMit, $\mathrm{P}$.

(1968): “Connaissance des Îles Canaries dans l'Antiquité”, Latomus 27, 362-391.

(1978): "La plus ancienne carte géographique du Maroc", Bulletin d'Archéologie Marocaine 11, 79-90.

Simões de Paula, E. (1946). Marrocos e suas relações com a Ibéria na Antiguidade, São Paulo.

TAUXIER, L.

(1867): "La Libye ancienne des colonnes d'Hercule au fleuve Sala", Annales des voyages de la géographie, de l'histoire et de l'archéologie 4, 7-74. 
(1885): "Le Mulucha ou Molochath (Oued-Makta)", Revue Africaine 29/169, 41-80.

(1886): “Le Métagonium \& l'Acra Mégalè”, Revue Africaine 30/180, 452-467; 31/184, 277-294.

Texier, J. G. (1976): “Polybe géographe”, Dialogues d'Histoire Ancienne 2, 395-411.

Thouvenot, R.

(1939): “La connaissance de la montagne marocaine chez Pline l'Ancien”, Hespéris 26/2, $113-121$.

(1948): “Défense de Polybe”, Hespéris 35/1, 79-92.

(1956): "Le témoignage de Pline sur le périple africain de Polybe (V, 1, 8-11)", Revue des Études Latines 34, 88-92.

Tissot, Сн. (1877): "Recherches sur la géographie comparée de la Maurétanie Tingitane", Mémoires présentés para divers savants à l'Académie des Inscriptions et Belles-Lettres 9, 1 ére Série, 139-322.

Tozer, H. F. (1897): A History of Ancient Geography, Cambridge.

TSIRKIN, J. B.

(1975): "Polybius's voyage along the Atlantic coast of Africa", Vestnik Drevnei Istorii 4, 111-114 (en ruso, título del resumen en inglés).

(1985): “The phoenician civilization in Roman Spain”, Gerion 3, 245-270.

Vivien de Saint-Martin, L. (1863): Le Nord de l'Afrique dans l'Antiquité grecque et romaine. Étude historique et géographique, Paris.

WALCKENAER, C. A. (1821): Recherches géographiques sur l'intérieur de l'Afrique septentrionale, Paris.

WARMington, B. H.

(1960): Carthage, London.

(1960-1969): Cartago, Barcelona.

Zecchini, G. (1991): “Teoria e prassi del viaggio in Polibio", [en] G. Camassa - S. Fasce (eds.), Idea e realità del viaggio. Il viaggio nel mondo antico, Génova, 111-141. 